\title{
Index for Volume 89
}

AUTHOR AND SUBJECT INDEX. Pages indicating errata are in italic. "S" indicates June abstract supplement. Publication number P-1999-1101-01O.

Abad, J. A., S72

Abad, P., 380

Abad, Z. G., S1, S72

Abawi, G. S., S1, S54, S84

Abbas, H. K., S1

Abbasi, P. A., S2

Abies concolor, Heterobasidion annosum, genetic structure in California, 546

Abney, T. S., S104

Aboshosha, S. S., S52

Abouzid, A. M., 701

Abstracts, author index of APS annual and division meeting presentations, S109

Abt, J. J., S65

Acidovorax avenae

—selective medium, S68

-on watermelon: seed detection, S96; variation, S 81

Acuna, I. A., S1

Adachi, K., S35

Adams, G. C., S2, S73

Adams, S. D., S32

Adaskaveg, J. E., 1056, S26

Adrian, M., 298

Agaricus spp., green mold, differential responses, S98

-A. bisporus: fruiting, sequence tag, S17; green mold, molecular analysis of strains, 308; Trichoderma green mold, steam pasteurization, S12

Agrobacterium spp.

-A. radiobacter: Ti plasmid acquisition, strain $\mathrm{K} 84$, 286; on tomato and cherry, biocontrol, 974

-A. tumefaciens: T-DNA transfer channel, gene requirement, S58; tumorigenesis, chromosomal gene, S58

-A. vitis: on Petunia, oncogene expression, S32; vir gene, nonpathogenic strain, $\mathrm{S} 81$

Agrostis palustris, dollar spot

- compost for biocontrol, S8

-management, zinc and manganese, S78

Aguilar-Rojas, O. I., S45

Ahmed, H. U., 64

Akashi, K., 1186

Akers, A., S40

Akimoto, T., S54

Alan, A. R., S2

Albiach-Marti, M. R., 336

Albugo spp.

-A. candida: on Brassica juncea, systemic resistance, incompatible isolate inoculation, 1226; host specialization, $\mathrm{S} 27$

- A. occidentalis, on spinach, fungicides, S94

Al-Dahmani, J. H., S2

Aldwinckle, H. S., S56

Alexander, N. J., S2

Alfalfa

—disease assessment, visual and remote, S105

- foliar pathogens: remote sensing, S30; visual disease assessment, S30

- phytoplasma, detection, S60

- vascular wilt pathogens, cultivar screening, S107

Alfonso, R. F., 64

Ali, S., S2

Allard, S., S58

Allen, R. D., S45

Allmaras, R. R., S37

Almond, anthracnose, epidemiology in California, 1056

Alptekin, Y., 840

Alternaria spp.: on citrus hybrids, in Florida, S59; on tangelo and lemon, host specificity, Florida, 851

- A. eichhorniae, growth and spore production, S71
-A. radicina, on carrot, seed assay for detection, S61

-A. solani, on tomato, resistance induced by salicylic acid, 722

Altier, N. A., S2

Alvarez, A. M., 366, 1007

Alvarez, E., S3

Alzate-Martin, A. L., 281

Amaranthus hybridus, Alternaria tenuissima, infection, S8

Amaud-Santana, E., S91

Amelanchier alnifolia, leaf and berry spot, response mechanism, S66

American Phytopathological Society

—abstracts, author index, S109

- annual and division meeting presentations, author index, S109

—annual report, 15

-award of distinction, 29

- excellence in extension award, 23

- excellence in industry award, 25

- excellence in teaching award, 24

-fellows, 20

-international service award, 25

-Lee M. Hutchins award, 26

— Novartis award, 27

—officers, representatives, and committees, 13

— presidential address, 17

-Ruth Allen award, 28

Ampelomyces quisqualis, mycoparasite of powdery mildew, glucanase encoding, 631

Amylostereum spp., taxonomic and phylogenetic review, $\mathrm{S} 73$

Anas, O., S3, S85

Anderson, J. A., 293

Anderson, J. D., S3, S53, S98

Anderson, M. G., S3, S98

Anderson, N. A., S31, S36

Anderson, R. J., S65

Andreotti, C., S18

Andrews, D. L., S28

Andrews, J. (Pa.), S63

Andrews, J. H. (Wis.), S10

Andries, C. L., S3

Andrivon, D., 679

Annis, S., S86

Anthurium, blight, biocontrol, 366

Anthurium andraeanum, bacteria blight, temperature effect, 1007

Antrodia sinuosa, on lemon, in Arizona, S7

Aparicio, F., 991

Apel-Birkhold, P. C., S3, S98

Aphanomyces cochlioides, resistance, evaluation technique, S8

Aphis gossypii, citrus tristeza virus vector, model system, 603

Apis mellifera, blueberry shock virus vector, 124

Apple

-bacterial and fungal pathogens, resistance induced by prohexidione-Ca, $\mathrm{S} 63$

— bitter rot, calcium salt for suppression, S99

-Botrytis cinerea, cyprodinil for, S72

- canker, wound treatment, S10

-decay, postharvest control, S18

-DPA drenches, postharvest, inoculum potential, S68

-fire blight: benzothiadiazole treatment, S50; epidemic analysis, S98; nectar effect on microbial antagonists, 39; prohexadione-calcium suppression, S88; secondary spread, prohexadione calcium, S37; tetracycline resistance transposons in bacteria, S70

- gray mold, postharvest control, antagonists and calcium chloride, S100 —orchard replant soils, biocide treatment, S50

- postharvest decay, Escherichia coli contamination, S36

-Pythium, metalaxyl sensitivity, S50

- Rhizoctonia-suppressive potential in roots of, 920

—scab: fenarimol use in symptoms, S6; fungicide efficacy in New York, S84; fungicides, S101

-wheat cropping in soil microbes, manipulation, S50

Apple stem grooving virus

- colorimetric detection, S42

-polymorphism analysis, sequence variants, 136

Arabidopsis thaliana

-bacterial wilt, hypersensitivity, 673

—salicylic acid-induced genes, S28

-turnip mosaic virus, cytoplasmic inclusion protein, S76

Arahana, V. S., S104

Araliaceae, Xanthomonas campestris on, strain heterogeneity, 646

Arbogast, M., 782

Arceuthobium spp.

-A. tsugense, biocontrol, S71

-A. vaginatum, on ponderosa pine, effect on song birds, S47

Archambault, C., S81

Arias, J., S91

Aris, V. M., S3

Armillaria spp.

-North American species, molecular markers, S101

-nuclear DNA content, North America, S39

Arnold, J., S84

Arthur, K., S39

Arul, J., S6, S14, S19, S38

Arumuganathan, K., S39

Asano, T., 314

Ascochyta spp., on pea, isolates in Alberta, S82

-A. lentis, on lentil, survival in residue, Canada, S28

Asher, M. J. C., 30

Ashizawa, T., S3

Asparagus

-Fusarium crown and root rot: hypersensitivity, $\mathrm{S} 33 ; \mathrm{NaCl}$ effect on roots, $\mathrm{S} 23$

-Fusarium root rot, chloride salt effect, S65

Aspergillus spp.

-A. flavus: alpha-amylase, inhibitors, S25; amylase gene, aflatoxin biosynthesis in corn kernels, 908; on corn, chitinase and glucanase in kernels, S36 on corn, host resistance, review, 113; on corn, kernel wax and maternal inheritance, S31; on corn kernels, alkaline protease, S15; corn trypsin inhibitor, antifungal activity, 902; S strain, temporal and spatial patterns, 761; $\mathrm{S}$ strains, comparison in Africa and North America, S18; synnemata and stipitate sclerotia in mutant, S50

-A. niger, in onion, seed infection, S73

Astua-Monge, G., S3

Audran, J.-C., 197

Aung, T., 518

Avgelis, A. D., 1050

Avila-Adame, C., S4

Avis, T. J., S12

Avocado, Phytophthora spp. on, microbial community structure, S87

Aycock, R., 352

Babadoost, M., S4

Bachand, G. D., S12

Bachman, M. S., 59

Bacillus spp., growth-promoting effect in crops, S65 
-B. thuringiensis, Bt Cry protein, serology, S86

Backhouse, D., S21, S56

Bacon, C. W., S27, S88

Bacon, R., S4

Bacteria, leaf colonization, strategy spectrum, 353

Bae, Y.-S., S4

Baek, J.-M., S4

Baenziger, P. S., S69

Bai, G.-H., 343

Bai, J., S4

Bailey, B. A., S3, S98

Bailey, D. J., 84

Bailey, J. E., S3

Bailey, K. L., S8

Baillieul, F., 197

Bains, P. S., S4

Baird, R. E., S5, S11

Bakker, P. A. H. M., 1073

Balasubramanian, S., S5

Baldridge, G., S80

Ballesteros, M., S29, S99

Banana

—black leaf streak, in Guam, S82

— crown rot, biocontrol, S85

Bandyopadhyay, R., S35

Banks, D., S15

Banniza, S., 414

Bardinelli, T. R., S93

Barg, E., 148

Barker, K. R., 612, S10

Barley

- covered smut, PCR detection, 212

-Fusarium head blight resistance, S24

-net blotch, virulence tagging, 176

- powdery mildew, blue-UVA effect, S22

-rust and scab resistance genes, polymorphism, mapping, S15

-scald, genetic structure of pathogen, 639

-stripe rust, genetics of resistance, 226

- triticonazole seed treatment, vigor enhancement, S40

Barley yellow dwarf virus

- control by vector modification, S38

- plant breeding tool, S17

-quantitative trait loci, S31

—on wheat, yield loss, S33

Barnes, C. W., S5

Barnes, G. D., 861

Barnett, J., S5

Bartlett, D. W., S5

Bashore, S., S77

Basidiospore, dispersion and culture process, S21

Basim, H., 1044

Basnayake, M. D. V. R., S98

Batchelor, W. D., S56

Batten, J. S., S5, S45

Bauer, P. H., S44

Baum, T. J., S82

Bauske, E. M., S32

Bazzi, C., S18

Beachy, R. N., 1022

Bean, cell death, cDNA clone, S36

Bean calico mosaic virus, squash leaf curl virus affiliation, characterization, 273

Bean golden mosaic virus

- on bean, isolate variability in Brazil, 262

-trans-dominant lethal, antiviral strategy, 480

Bean yellow mosaic virus, coat protein, Fab antibody, S48

Beattie, G. A., 353, S48

Beaulieu, C., S59

Beaulieu, J., 915

Becherer, H. E., S9

Beck, J. J., S5

Becker, C. M., S98

Becker, J. O., S84

Becker, K. B., 796

Beckham, K. A., S62

Becton, C. M., S67
Bedford, K. E., S72

Been, T. H., 583

Beer, S. V., S56

Beet necrotic yellow vein virus, on sugar beet, rhizomania, 1000

Beet pseudo-yellows virus, distribution and molecular variation, 707

Beet soilborne mosaic virus, nucleotide sequence, S45

Bélanger, R. R., 728, S12, S51, S67

Bell, A. A., S6

Bell, J., S52, S100

Bemisia tabaci

— geminivirus vector, molecular marker, S91

- squash leaf curl virus vector, occurrence in body, 239

Bender, C. L., S25

Bender, C. M., S8

Benhamou, N., 506, 728, S19, S14, S23, S87

Benítez, T., 254

Bennett, D. L., S68

Bennett, R. N., 1226

Benny, U., S32

Bennypaul, H., S4

Benson, D. M., S6

Bergstrom, G. C., S71

Berkett, L. R., S47

Bernardo, I., 1169

Bernier, J., S6

Bernier, L., 915, S22, S26, S76

Berton, O., S6

Bertrand, H., S102

Bertrand, P. F., S93

Bérubé, J. A., 915, S44, S101

Bessis, R., 298

Best, V. M., 1127

Beta vulgaris, beet cyst nematode, soil suppressiveness, 434

Beyer, D. M., S3, S12, S98

Bezerra, I. C., 823

Bhaskara Reddy, M. V., S6, S19, S38

Bhat, A. I., S6, S15

Bhat, R. G., 1218, S7

Bhatia, A., S104

Bhatt, G., S7

Bigelow, D. M., 761, S7

Biggerstaff, C. M., S7

Biggs, A. R., S98, S99

Biles, C. L., S89

Binns, M. R., 1104

Biological control

-Ampelomyces quisqualis, mycoparasite of powdery mildew, glucanase encoding, 631

- Bacillus subtilis and Trichoderma harzianum for kidney bean root rot, S24

—bacteria for anthurium blight, 366

- bacteria, phloroglucinol in selection, S88

-bioherbicides, Drechslera and Exserohilum spp., nontarget host reaction, S13

-chitinolytic bacteria for cucumber Fusarium wilt, 92

-Coniothyrium minitans for Sclerotinia sclerotiorum, long-term sanitation, 141

- crown gall of tomato and cherry, dose response and model, 974

-Fusarium oxysporum and Pseudomonas putida for flax Fusarium wilt, 1073

-Fusarium wilt of tomato by nonpathogenic species, mechanisms and dose response, 1152

-microbial antagonists for fire blight of pome fruits, nectar effect, 39

- Pantoea agglomerans for fire blight of apple and pear, S62

- Pseudomonas syringae and Alternaria for Canada thistle, S8

—rhizobacteria, growth-promoting, for foliar pathogens, S65

- Stenotrophomonas maltophilia, on Bipolaris on tall fescue, 817
- Streptomyces transposon Tn5353, luciferase gene, S67

-Trichoderma and Pseudomonas for wheat takeall control, S22

-Trichoderma harzianum: molecular analysis of strains, 308; to Rhizoctonia solani, transformants with chitinase, 254

-Ulocladium atrum for Botrytis spp., 868

-vegetable transplants, commercial potential, S39

Bipolaris sorokiniana, on fescue, biocontrol, 817

Bird, C. B., S1

Bish, E. B., S29

Blaich, R., S70

Bliss, W. O., S7

Blodgett, J. T., S7, S8, S37

Blom, P. E., 1112

Blom, T. J., S29

Blueberry

— fruit rotting fungi, Michigan, S69

— pest management in Georgia, survey, S69

Blueberry shock virus, pollen-borne, honeybee transmission, 124

Blumeria graminis, on cereals, penetration resistance breakdown, nonhosts, S89

Boal, R., S30

Boari, A. J., S57

Boccardo, G., 303

Boehm, M. J., S26, S39, S46

Bois, D., S91

Boland, G. J., S8

Bond, J. P., S8

Bond, W. P., S8

Bonde, M. R., S8

Bonfiglioli, R. G., 894

Bongiovanni, M., 380

Bonsall, R. F., 470, S35, S63

Boonstra, H., S27

Boppuri, L., S32

Bordas, A. C., S8

Borejsza-Wysocka, E. E., S56

Borhan, M. H., S90

Borlee, B. R., S66

Borthakur, D., S37

Bos, L., 148

Bostock, R. M., 962, S82

Bothast, R. J., S69, S73

Botryosphaeria spp.: molecular phylogeny, internal transcribed spacer, rDNA sequence, S90; species complexes, inter simple sequence repeat as tool, S90

-B. dothidea, RAPD marker differentiation, S74

Botrytis spp.: biocontrol by Ulocladium atrum, 868; on faba bean, factors, S42

$-B$. cinerea, antifungal agent sensitivity, $\mathrm{pH}$ effect, S94; on begonia, calcium chloride for control, S42; benzimidazole and dicarboximide effect, analyses, S88; captan, thiram, and mancozeb effect, greenhouse crops, S20; on grape, defense induction, 197; laccase, pterostilbene dehydrodimer, characterization, 298; sibling species, sympatry, 967; on tomato fruit, ultraviolet treatment, S14

Boudabbous, A., S67

Boudreau, M. A., S80

Boulter, J. I., S8

Bourque, J., S71

Bouzar, H., 328

Bowden, R. L., 182

Bowen, K. L., S10, S32

Bowers, J. H., S8

Boyetchko, S. M., S8

Brady, S. F., S66

Brainard, K. A., 942

Brantner, J. R., S8, S104

Brassica spp.

- B. juncea, white rust, resistance induced by incompatible isolate, 1226 
-B. napus: blackleg, resistance and introgressions, 1200; blackleg, resistance gene, 169; recombinant lines, resistance to Leptosphaeria maculans, S90

Braun, E. J., S7

Bremia lactucae, sporangia, periodicity, S11

Brenneman, T. B., S93

Breuil, A.-C., 298

Breuil, C., S9, S26, S34, S39

Bridge, P D., 414

Brioso, P. S. T., S100

Brisson, J., S81

Brisson, L. F., S27, S43

Bristow, P. R., 124

Britton, K. O., S9

Britz, H., S9

Brlansky, R. H., S61

Brooks, C., S26, S99

Brooks, R. W., S9

Brown, E. M., S3

Brown, J. (Canada), S12

Brown, J. K. (Ariz.), 239, 273, S91

Brown, L. G., S91

Brown, R. L., 113, 902, S9, S15, S28

Brown, S. E., S9

Brown, W., S29

Browne, G. T., S9

Brown-Rytlewski, D., S10

Brun, H., 169, 1200

Bruns, T. D., 546

Bruton, B. D., S10, S89, S95

Brygoo, Y., 967

Bucchi, F., S18

Buck, J. W., S10

Bugiani, R., 947

Bujold, I., S10

Bull, C. T., S8, S16

Bulluck, L. R., III, S10

Bulman, S. R., 392

Burch, K. B., S10

Burdon, J. J., 639

Burgess, L. W., 1126, S21, S56

Burke, K. C., S52

Burkhead, K. D., S73

Burkholderia cepacia, copper sensitivity, S48

Burr, J. A., S84

Burr, T. J., S33

Bushnell, W., S80

Butler, E. E., S40

Butternut, canker, dsRNA detection, S74

Buyer, J., S26

Byrne, J. M., S10, S99

Byrne, T., S9

Cabbage, white mold, fungicides, S16

Cabrera, O., S11

Cactus

— phytoplasma, in Mexico, S45

— viruses, in U.S. southwest, S15

Cadenas, M., S30

Caesar, A. J., S55

Caesar-Tonthat, T. C., S11

Cai, G., S11

Caldwell, W. D., S17

Callahan, T. M., S79

Calvert-Evers, J., 303

Camara, M. P. S., S99

Camero, R., 1038

Campbell, C. L., 17, S3, S23

Campbell, H. L., S11

Canaday, C. H., S11, S93

Canihos, Y., 851

Canola

—brown girdling root rot, yield loss, S40

- disease controlled by reduced tillage and crop rotation, $\mathrm{S} 43$

Cao, T., 962

Capell, B., S65

Cappaert, M. R., 782
Capsicum spp.

-C. аппиит, bacterial spot, major resistance genes, 1066

-C. pubescen, hypersensitivity, Xanthomonas campestris, $\mathrm{S} 53$

Cardwell, K. F., S18, S70

Carey, W. A., S57

Carisse, O., S6, S10, S11, S13, S20, S23, S77, S84

Carling, D. E., 942, S5, S11

Carnation, Fusarium wilt, detection by PCR amplification, 1169

Caron, S. J., S12

Carraro, L., 894

Carras, M. M., S102

Carrot

— gray mold, resistance induction, S6

-root lesion nematode, band fumigation, S50

Carson, M. L., S12

Carter, D. A., 942, S56

Cartwright, R. D., 176, S1, S53, S95, S96

Carver, T., S89

Casalongué, C., 840

Cassava, bacterial blight, semiselective medium for isolation, 591

Cassidy, B. G., S94

Castagnone-Sereno, P., 380

Castaigne, F., S6, S19

Castellanos, G., S47

Castello, J. D., S12

Castle, A. J., S27

Caswell-Chen, E. P., 68

Catharanthus roseus, Phytophthora, in Hawaii, S78

Catlin, N. J., S12

Catranis, C. M., S12

Cauliflower mosaic virus

-hypersensitivity, tobacco, S16

—in yeast, polycistronic 35S RNA, S71

Cavallarin, L., 737

Cavanni, P., 947

Celebi, F., S12

Cephalosporium maydis, on corn, in Egypt, S23

Ceratocystis fagacearum, on oak, cyanide-resistant respiration and virulence, $\mathrm{S} 102$

Cercospora spp., cercosporin production, degradation, S53

-C. arachidicola, on peanut, temperature and wetness effect, 653

-C. nicotianae, cercosporin resistance, gene characterization, $\mathrm{S} 22$

Ceresini, P. C., S12

Cerkauskas, R. F., S12

Cevik, B., S13

Chaky, J., S13

Chandler, C. K., S45, S52, S86

Chandramohan, S., S13

Chandrika, R., S13

Chaney, H., S95

Chang, C. J., S9, S15

Chang, K. F., S13, S35, S82

Chantre, N., 533

Charest, J., S13, S20

Charest, P. M., S43, S44, S59, S83

Charkowski, A. O., S14

Charles, M. T., S14

Charlet, G., S38

Charudattan, R., S13, S71, S86

Chase, A. R., 646

Chastagner, G. A., S14

Chatterjee, A., S14, S22

Chatterjee, A. K., S14, S22

Chellemi, D. O., S41

Chen, C. Y., S14

Chen, G., S14

Chen, J., S15

Chen, L., 1022

Chen, W. (Ill.), S15

Chen, W. (S. Africa), S8

Chen, X. (Pa.), 308

Chen, X. M. (Wash.), 226, S15
Chen, Y.-S., S60

Chen, Z.-Y., 113, 902, S9, S15

Cheon, J. U., S15

Cherif, M., S67

Cherry, crown gall, biocontrol, 974

Cherry mottle leaf virus, RT-PCR detection, S36

Chessin, M., S15

Chèvre, A. M., 1200

Chida, Y., 1186

Chiocchetti, A., 1169

Chittoor, J., S104

Chitwood, D. J., S52

Chlamydomonas reinhardtii, phytotoxicity, model system, S2

Cho, E. K., S93

Cho, J. H., S93

Choi, H. S., S15

Choi, I.-R., 1182

Choi, S. (Kans.), S4

Choi, S. H. (Korea), 928

Choi, W., S15, S64

Choi, Y. G., 877

Chong, J., S31

Chopin, F., 298

Christ, B. J., S46, S64

Chrysanthemum spp.

-C. carinatum, phytoplasma, localization in host and vector, 894

-C. morifolium, virus-like particles in leaf cells, $\mathrm{S} 48$

Chrysanthemum stem necrosis virus, new in Brazil, 823

Chtioui, Y., 668, S16

Chun, W., S60, S61, S65

Chung, K.-R., S22

Chung, Y. R., 92

Cintas, N. A., S16

Circulifer tenellus, vector for Spiroplasma citri, internal movement, 1144

Citrus

- canker, spread in Florida, S29

- green mold, postharvest washing, sodium bicarbonate, $\mathrm{S} 74$

-hop stunt viroid on, cachexia and xyloporosis, 568

- melanose, weather factors, S35

- postharvest fungicides, resistance in Penicillium, 716

-tangelo and lemon, Alternaria brown spot, host specificity, 851

Citrus tristeza virus

- aphid vector and spatial dynamics, stochastic modeling, 603

-aphid vector, transmission, S61

— assessment and survey, aphid vector, 487

- molecular comparison of isolates, S33

- molecular variation, California, S67

-RNA polymerase gene, characterization, S13

-sequence divergence, 336

Citrus viroid, group II variants, symptom expression, cover photo, July

Ciuffetti, L. M., 444

Claflin, L. E., S16, S64

Clardy, J., S66

Clark, G. M., S16

Clarke, B. B., S77

Clavibacter michiganensis

—on potato: HR-elicitor, S56; mapping, S9

-on tomato: detection in seed, PCR assay, S90; fruit spot development, S100; genomic variation, S52; population characterization, S103; soil moisture effect, S7

Claviceps spp., on sorghum, species differentiation, sequence analysis, S102

-C. africana: genetic variability, S64; on grain sorghum, survival, S16; on sorghum, hybrid reaction, S35

- C. purpurea, peptide synthetase gene, cloning, S58 
Clayton, M. K., S79

Cleveland, T. E., 113, 902, S9, S15, S28, S31

Cobb, F. W., 546

Cochliobolus heterostrophus, cercosporin effect, transgenic expression, S79

Cochran, A. J., S104

Coconut, etiology of uncertain diseases, S37

Cody, B. R., S16

Coffman, C. B., S53

Cognet, S., S37

Cohen, J. D., S54, S100

Cohen, S. D., S16

Cohen, Y., 1138

Colburn, G. C., S16, S53

Cole, A. B., S16

Colletotrichum spp.: on almond, conidial morphology, cover photo, November; on postharvest fruit, rDNA sequence, S42; on strawberry, splash dispersal of conidia, 555

-C. acutatum: on almond, epidemiology in California, 1056; on strawberry, secondary spores, S44

-C. gloeosporioides: on Arachis pintoi, genetic diversity, S38; on Malva pusilla, protein kinase homologs, $\mathrm{S} 14$

- C. graminicola, spore germination, surface characteristics, $\mathrm{S} 13$

-C. lindemuthianum, on bean, resistant gene Co-6, 281

-C. orbiculare: on watermelon, fungicides, S90; on watermelon, spatio-temporal model, S97

Collin, J., S17

Collins, D. J., S17

Collins, D. P., S17

Collins, S., S17

Collopy, P. D., S17

Colquhoun, I., S17

Colyer, P. D., S17

Comeau, A., S17

Comstock, J. C., S17

Conifers, rust fungi, allelic diversity in $10 \mathrm{spp}$., S22

Coniothyrium spp.

-C. minitans: biocontrol agent for Sclerotiniainfected crops, 141; cover photo, February

-C. zuluense, on Eucalyptus spp., characteristics in South Africa, S80

Conklins, M. A., S25

Conner, R. L., S56

Connolly, J. H., S18, S99

Conway, W. S., S18, S36

Cook, D. L., S75

Cook, R. J., S35

Cooperband, L. R., S75

Copes, W. E., S69

Coprinus cinereus, RAPD marker mapping, S48

Corn

-aflatoxin, resistance, kernel wax effect, S28

-aflatoxin contamination: host resistance, review, 113; nitrogen effect, Louisiana, S78

-Fusarium spp. interaction, ear rots, mycotoxins, 1028

— gray leaf spot: epidemiology and management in USA, S101; forecasting, S104

-head smut, development in shoot apex, 247

- kernel resistance, Aspergillus and Fusarium, S9

-mutants, bacterial colonization, S48

-novel virus in Israel, S70

-Phaeosphaeria leaf spot, resistance inheritance, S12

- phytoanticipin detoxification, Fusarium monili-

forme, genetics, S27

— pink ear rot, genes, S58

-root rot, conservation tillage effect in Mexico, S52

-rust, damage thresholds in inbreds, S83

- seed infection cytology, PRms protein, 737

- Stewart's disease, prediction, S105

- sugarcane mosaic virus, resistance, loci mapping, 660

- yield and agronomic characters, Bt toxin, teflu- thrin, azoxystrobin, and propiconazole, $\mathrm{S} 101$

Cornelissen, B. J. C., 156, 1131

Costa, G., S18

Costa, J. B., S33

Cotton

-aflatoxin contamination in seed, S strain, 761

—crown gall, Rhizoctonia and Agrobacterium synergism, S6

-Fusarium wilt, nematode relation, S17

—nematodes, Louisiana deltar region, S51

-reniform nematode, in Tennessee, S75

-root-knot nematode and black root rot, temperature effect and histopathology, 613

-Xanthomonas campestris, terpenoid biosynthesis, S60

Cotty, P. J., 761, S18

Coutinho, T. A., S9, S73, S75, S80

Coutts, R. H. A., 1050

Cover photo

- citrus viroid, symptoms and variants, July

-Colletotrichum spp., from almond, conidial morphology, November

-Coniothyrium minitans on bean, February

-Fusarium oxysporum: on tomato, macroconidia, September; lycopersici, GUS transgenic mutant in tomato, December

-Melampsora larici-populina, on poplar, March

-oleander leaf scorch, symptoms, January

- Plasmodiophora brassicae, on turnip, April

- soybean dwarf luteovirus, May

- Sphaerotheca fusca, on cucumber, biocontrol, August

- Stemphylium vesicarium, on tomato and pear leaves, October

-Toxoptera citricida on citrus, June

Cowgill, W., S100

Cowpea, rust, hypersensitivity, ultrastructural analysis, S54

Cowpea chlorotic mottle virus, RNA 1 mutation, phloem-dependent movement, S63

Cowpea mosaic virus, cucumber mosaic virus comparison, synergism, S21

Cranberry

- fruit-rotting fungi, distribution in New Jersey, 218

- Monilinia oxycocci, resistance, 1127

-multiplex detection, DNA arrays in rotorod spore samplers, S45

Crawford, W. E., S62

Creemers, P., S63

Crippen, D. L., 1193, S77

Croft, B. J., 877

Cronartium ribicola, on white pine

- Cro $r$ I, cDNA, cloning, S88

- genetic structure in Canada, 915

— major gene resistance, 861

—on sugar pine, virulence inheritance, 192

-in Wisconsin, S19

Cronjé, C. P. R., S37

Crowe, F. J., S59

Crowley, D. E., S87

Cryphonectria parasitica

- on chestnut, biocontrol organism for, S100

-hypovirus 1, sequence similarity in Europe and Asia, S46

Csinos, A. S., S18, S49, S58, S59

$\mathrm{Cu}, \mathrm{R} . \mathrm{M} ., \mathrm{S} 46$

Cuasquer, J. B., S47

Cubeta, M. A., S12, S16

Cucumber

- Colletotrichum lagenarium on, acquired resistance, cycloheximide, S80

-damping-off, Enterobacter cloacae for suppression, S101

-Fusarium crown and root rot, epidemiology in British Columbia, S59

-Fusarium wilt, biocontrol with bacteria, 92

-leaf spot, organisms in North Carolina, S23

- phytoalexin production, S51

- powdery mildew, ultrastructure, 728 —wilt and root rot, genetic diversity in Fusarium, 161

Cucumber mosaic virus

- on Ajuga reptans, characterization, S26

-on cowpea, virulence and amino acid change, 1186

-RNA 3, characterization, S38

-on tomato, bacteria for growth promotion, S67

-on weeds, aphid transmission, S34

- on yellow pasion flower, in Brazil, S27

Cucumis melo

—dieback, resistance, S35

-Fusarium wilt, resistance, S38

Cucurbit

- powdery mildew, noncucurbit hosts, S102

— viruses, cropping pattern effect, S19

-yellow vine bacterium, insect endosymbiont, S95

Cucurbit yellow stunting disorder virus

- coat protein gene, molecular characterization, 1050

- distribution and molecular variation, 707

Cucurbita pepo, ilarvirus, characterization, S83

Cui, Y., S14, S22

Culbreath, A. K., S6, S94, S95

Culver, J. N., S18

Cummings, S. M., S93

Cummings Carlson, J. E., S19

Cuperus, C., 148

Cuppels, D., S19, S67, S81

Curcuff, R., S6

Curio-Penny, B., 796

Cyathus olla, canola stubble fiber decomposition by, $\mathrm{S} 72$

Cyclamen persicum, Botrytis spp., biocontrol with Ulocladium, 868

Cyclaneusma minus, on pine, antagonism and hyperparasitism, S81

Cylindrocladium spp., species comparison, S56

Cymbidium mosaic virus, detection, immuno-capillary zone electrophoresis, 522

Cytospora spp., on Eucalyptus spp., Valsa teleomorph, S2

Daboussi, M.-J., 1169

Dagry, K. M., S19

Dahir, S. E., S19

Daleo, G. I. I. B., 840

Daleo, G. R., S31

Dally, E. L., S100, S102

Damann, K. E., S15, S28, S78

Damicone, J. P., 653, S19, S94

Damrongkool, P., S58

Damsteegt, V. D., 374

D'Andrea, E., 303

Dandurand, L. M., S19

Dankers, W. A., S54

Dann, E. K., 598

D'Arcy, C. J., S34

Dargent, R., 247

Datnoff, L. E., S19, S70

Daub, M. E., S22, S53

Davis, E. L., S82, S87

Davis, G., S30

Davis, M. J., S3, S19

Davis, R. E., S100, S102

Davis, R. M., S36

Dawson, W. O., 336

Day, M. E., S46

Dayan, F. E., S94

Deacon, J. W., S49

Dean, R. A., S15, S38, S42, S64, S88

de Ávila, A. C., 823

de Barros, E. G., 281

de Bruijn, F. J., 328, S52

de Carvalho, G. A., 281

de Cock, A. W. A. M., S45

Défago, G., S49, S88

degli Ivanissevich, S., 748 
de Groot, F., 1131

de Haas, B. H., 868

DeJong, T. M., 962

de Kochko, A., 1022

Delen, N., S20

Dell, K. J., S31

Delourme, R., 169

Del Rio, L. E. , S105

Demirci, E., S41

Denny, T. P., 1233, S7

Deom, C. M., 934, S6, S63, S83

de Paul Júnior, T. J., 281

DePriest, P. T., S99, S102

Derby, J., S8

Derckel, J.-P., 197

Derie, M. L., S20

Derksen, D., S28

Dernoeden, P. H., S99

Dery, P. D., S101

DeScenzo, R. A., 884

Desilets, H., S29, S87

de Souza, J. T., S20

Despins, T., S44

Desvoyes, B., S20

de Villiers, G., S29, S99

Dewdney, M., S13, S20

Dewey, F. M., 868, S4

DeWolf, E. D., S20, S105

de Zoeten, G. A., S73

Diaby, M., S20

Diallo, H., S21

Diaporthe phaseolorum, on soybean, molecular detection in seed, 796

Díaz, J. A., 1038

Díaz-Ruíz, J. R., 1176

Dickson, D. W., S65

Dicliptera sexangularis, geminiviruses from, S72

Didymella bryoniae

-on cucurbits, worldwide collection, variation, S42

-hypovirulence, dsRNA association, S79

- virulence and cell wall-degrading enzymes, S89

-on watermelon and cantaloupe, benomyl sensitivity, S42

Diers, B. W., 598

Dietz, J. M., S105

DiLeone, J. A., 974

Dill-Macky, R., S21, S24, S55, S60

Diner, A. M., S21

Ding, X., S82

Discula umbrinella, DNA, analysis protocol, S16

Disease, soil and plant interaction, spectroscopy and metal study, S107

Disease forecasting, wetness duration, 668

Disease management, decision tools, evaluation, S52

Di Terlizzi, B., 991

Dobinson, K. F., S54

Dodo, H. W., S61

Domanski, D., S79

Domier, L. L., 343, S58

Donohue, C., S64

Donovan, N. J., S21

Doster, M. A., S21

Douds, D. D., S21, S55

Doughty, K. J., 1226

Douglas, M. P., S21

Douglas, S. M., S43

Doussinault, G., 533

Dowd, P. F., S36

Dowler, C. C., S18

Doxtader, D. C., S43

Driscoll, S. J., S60, S107

Druffel, K., S44

Dry, I. B., S25

Dubey, T., S21

Dubin, H. J., S52

Duffus, J. E., S57, S85

Duffy, B., S22, S88

Duick, J. W., S22, S28
Duijff, B. J., 1073

Duke, C., S69

Dumenyo, C. K., S22

Duncan, K. E., S22

Duplaga, B., S30

Duplaga, W., S30

Dupper, G. E., 192

Dusabenyagasani, M., S22

Duthie, J. A., 653, S90, S97

Dutilleul, P., 74

Earle, E. D., S2

Eastburn, D. M., S34

Eayre, C. G., S22

Eberlein, C. V., S19

Echinacea spp., Alternaria leaf spot, S13

Eckert, J. W., 716

Eckhardt, L. G., S18

Edelson, J. V., S19

Edwards, H. H., S22

Effertz, R. J., 293

Egan, A. R., S85

Egger, K. N., S101

Ehara, Y., 1186

Ehrenshaft, M., S22

Ehret, G. R., S37

Eisley, J. B., 840

Eken, C., S41

Ekramoddoullah, A. K. M., S88

El-Allaf, S. M., S23

El-Assiuty, E. M., S23

Elbasher, K. A., S56

El Bassam, S., S23

Elfving, D. C., S50

Elias, E., S74

Elings, S., 789

Elkins, R. B., S31

Ellingboe, A. H., S20, S105

Elliott, M. L., S23

Ellis, M. A., 555, S24

Ellis, P. J., S29, S99

Elmer, W. H., S23

El-Sattar, A., S60

Elwakil, M. A., S71

Emele, L. R., S23

Emery, K. M., S23

Enebak, S. A., S24, S57

Engel, S. R., 884

Ens, W., S32, S70

Entomosporium mespili, conidiogenesis, ultrastructure, S53

Enyedi, A. J., 722

Epichloë festucae, endophytes, genetics, S77

Epidemiology

—mixed host population, mini-review, 984

- sample size, disease prediction, spatial hierarchy, 770

- take-all, primary and secondary infection dynamics, 84

Erincik, O., S24

Errampalli, D., S24

Errata

—vol. 89 , no. $5,1999,712$

—vol. 89, no. 6, 1999, 840

Erwinia spp., pathogenicity factors, global regulator genes, S22

-E. amylovora: on apple, attacin $\mathrm{E}$ effect on resistance, S56; in apple, endophytic in tissue, S102; bacteriophage for control, S27; on crabapple, water factors, S62; plasmid, sequence analysis, S51; on pome fruit, nectar effect on microbial antagonists, 39

-E. carotovora: on calla lily, copper effect, S29; tissue macerating enzymes, temperature effect, S14

-E. herbicola, foliar pathogen, 353

-E. stewartii, on corn, kernel infection, S52

- E. tracheiphila, on cucumbers, PCR for detection, S10
Erysiphe spp.

-E. cichoracearum, on Monarda didmya, tolerance, S9

$-E$. graminis, on wheat, resistance gene, residual effect of gene MIRE, 533

Esker, P. D., S105

Espinha, L. M., S27

Essenberg, M., S60

Estevez de Jensen, C., S24

Et-touil, K., 915

Eun, A. J.-C., 522

Euscelidius variegatus, phytoplasma vector, localization in host, 894

Eutypa spp., on grape, genetic analysis in California, 884

Evans, C. K., S24

Evans, I. R., S39

Evans, J. R., S63

Evans, N., S24

Evans, T. A., S98

Evans, W. B., S53

Evensen, C., S78

Eversmeyer, M. G., S24

Evert, K., S54

Everts, K. L., S25, S53

Faggian, R., 392

Faghihi, J., 204

Fakhoury, A. M., 908, S25

Fakhr, M. K., S25

Falk, B. W., 707, S67

Fang, E., S15, S64

Faria, J. C., 262

Faris, J. D., 293

Farnham, M. W., S38, S42

Fauquet, C., 1022

Feldman, M., 840

Feliciano, C. J., S31

Fellers, J. P., S25

Fernandez, D., 407

Fernandez, G. E., S1, S29

Fernandez-Pavia, S. P., S51

Fernando, W. G. D., 74, S37

Ferrand, K. H., S81

Ferree, D. C., S24

Ferris, J. M., 204

Fery, R. L., S77

Fessehaie, A., 591

Festuca arundinacea, endophyte-infected, seed germination, $\mathrm{S} 84$

Fichtner, E., S25

Ficke, A., S25

Ficus carica, fungal decay, California, S21

Figueira, A. R., S57

Filion, M., S25

Finckh, M. R., 64

Fisher, J. R., S26

Fisher, K. H., S83

Fitt, B. D. L., S24

Flak, L. A., S75

Flax, Fusarium wilt, antagonism by Fusarium and Pseudomonas spp., 1073

Fleet, C., S9

Fleischer, S. J., 1112

Fletcher, J., 1144, S10, S95

Flynn, J. F., S29

Fokkema, N. J., 141

Foreman, G. L., S106

Förster, H., 1056, S26

Fortin, M., S4, S60, S76

Fortini, D., 967

Fortnum, B. A., S57

Fragkiadakis, G A., 161

Francl, L. J., 293, 668, S2, S16, S20, S105

Fravel, D. R., 1152, S26

Frederick, R. D., S8, S102

Freeman, S., 456

French, R., 1182

Frick, M. M., S56 
Friesen, T. L., S105

Frohberg, R. C., S32

Fry, J. D., S71

Fry, W. E., S30, S36, S50

Fukui, H., 366, 1007

Fukui, R., 366, 1007

Fulbright, D. W., S52, S100, S102, S103

Fumigation

—dazomet, forest nursery application, S37

- methyl bromide, tobacco and tomato seed beds, S18

Fungicides (general) (see also Fungicides, specific) -autography and microtiter assay, protocol, S96

- rain-fastness and redistribution for Oomycetes, S63

— wheat seed treatment, take-all, model, 954

Fungicides (specific) (see also Fungicides, general)

—imazalil, Penicillium spp. resistant to, 716

-kresoxim-methyl: for disease control in pecan, apple, and cucurbit, S93; mode of action, host physiology effects, S40; on ornamentals, S16; performance on apple, pear, grape, pecan, and cucurbit, S28

-mancozeb, rain-fastness formulation, S63

-o-phenylphenol, Penicillium spp. resistant to, 716

- phenylamide, Phytophthora resistance, 754

- RH-7281: foliar oomycete disease control, S85; oomycete control, resistance risk, S88

-thiabendazole, Penicillium spp. resistant to, 716

Furuya, H., 47

Fusarium spp.: on hosta, root and crown infection, S82; on shortleaf and longleaf pine seed, S57

-F. avenaceum, phytotoxin, on Rubus spp., S34

-F. circinatum, populations, in South Africa, S9

$-F$. graminearum: on corn ear, $F$. moniliforme interaction, mycotoxins, 1028; on wheat, resistance and molecular markers, 343; on wheat, survival and inoculum potential, S60

-F. moniliforme: on corn, infection cytology, $\mathrm{PRms}$ protein, 737; on corn, selective medium, S27; on corn, stem and ear borer relation, S70; fumonisin $\mathrm{B}_{1}$ produced by, suppressed by Trichoderma, S88; fumonisin biosynthesis, FIC1, S72

-F. oxysporum: $24 \mathrm{kDa}$ protein from, fungal effect, S98; on basil, biocontrol, S26; on birdsfoo trefoil, epidemiology, S2; on carnation, detection by PCR amplification, 1169; on collard and kale, resistance, S38; on cucumber, genetic diversity and RAPD fingerprinting, 161; on date palm, diagnosis, 407; DNA banding pattern, S66; filtrates, weed control, S3; on flax, variability, S64; flax wilt suppressed by, 1073; on lettuce, in Japan, S87; lycopersici, GUS transgenic mutant in tomato, cover photo, December; nit mutants, selective medium, S56; on tomato, biocontrol with nonpathogenic species, 1152; on tomato, genetic diversity, molecular markers, S11; on tomato, macroconidia, cover photo, September; on tomato, population genetics, 623; on tomato, spatial distribution and dissemination in soil, 831; on tomato, vegetative compatibility groups, 156 ; on tomato, virulence and pathogenicity in gammairradiated mutant, 1131

$-F$. proliferatum, molecular variations in populations, S56

$-F$. solani, on bean, suppression by soil aluminum, 47

$-F$. subglutinans, on mango, malformation and GUS transformants, 456

Futagawa, M., S94

Gabriel, D. W., S33

Gadoury, D. M., S6, S23, S25, S70

Gaeumannomyces graminis

—osmotic potential, S23

-on wheat: epidemic dynamics, 84 ; seed treatment, fungicide efficacy, model, 954
Gagné, P., S26

Gal-On, A., S79

Garbelotto, M., 546

Garibaldi, A., 1169

Garling, D. C., S26

Garnsey, S. M., 336, 603, S33, S83

Garrett, K. A., 984, S26

Garrido-Ramirez, E. R., S71

Gaskins, V., S26, S99

Gaspar, J. O., S27

Gaudet, D. A., S44

Gay, P. A., S61

Gene-for-gene system, coevolution, human perturbations, properties, 811

Geranium, virus isolate $\mathrm{Gr} 57$, genome organization, $\mathrm{S} 40$

Gergerich, R. C., S21, S48

Gerhardt, S. A., S27, S41

Gerlagh, M., 141

Gessler, C., 748

Getz, R. R., S32

Gibberella spp.

-G. fujikuroi, mating population H, MAT-1 and MAT-2 isolates, $\mathrm{S} 75$

-G. zeae: ascospore discharge, S3; biocontrol, S39; sexual recombination, 182; on wheat, modeling of disease foci, 74; on wheat and corn debris, perithecial development, S10

Gibson, G. J., 603

Gigaspora sp., light effect, ecology, S21

-G. gigantea, hyphal branching, ultraviolet light effect, S55

Gilbert, J., 840

Gilbert, M., S27

Gilbertson, R. L., S7, S61, S68, S71

Gildow, F. E., 374

Gilijamse, E., S27

Gill, B. S., 293

Gill, J. J., S27

Gillaspie, A. G., Jr., S94

Gillett, J. M., S69

Gilligan, C. A., 30, 84

Gillis, B., S31

Ginseng, Cylindrocarpon destructans and Fusarium spp., seed and root rots, S65

Gioria, R., S27

Gipson, R., S95

Giraud, T., 967

Gitaitis, R. D., S5, S11, S81, S96

Gleason, M. L., S7, S44, S59, S90

Glenn, A. E., S27

Globodera spp.

-G. rostochiensis, G. pallida compared to, on potato, infestation foci model, 583

-G. tabacum, on tobacco, nitrogen and fosthiazate effect, S37

Glomus spp., molecular tools for study, S25

Goates, B. J., S28

Godoy-Lutz, G., S91

Godshall, M. A., S30

Goeke, S. C., S48, S93

Goellner, M., S82

Goh, Y. K., S28

Goins, E. W., S29, S99

Gold, J., 840

Gold, R., S28, S40, S93

Gold, S. E., S22, S28

Goley, E. D., S47, S102

Golino, D. A., S66

Gomez, A. M., S28

Gomez, G., 884

Gómez, P. L., S3

Gooding, G. V., Jr., 352

Goodman, R. M., S66

Goodwin, P. H., S14

Goodwin, S. B., S28

Goossen-van de Geijn, H. M., 141

Gorbet, D. W., S94

Gordon, D. T., S65
Goregaoker, S. P., S18

Gosselin, C., S14

Gossen, B. D., S28, S35

Goth, R. W., S29, S99

Gotlieb, A. R., S47

Gotoechan, H., S29

Gottwald, T. R., 487, 603, S29

Goudriaan, J., 868

Grabowski, M. A., S29

Grace, P. R., S52

Gracia-Garza, J. A., S29

Graef, G. L., S104

Grafton, K., S64

Graham, J., S29

Graham, M. Y., S29

Graham, T. L., S29

Grajales, O., S3

Granatstein, D. M., S50

Grand, L. F., 612, S6

Granett, J., S47

Grape

—black rot, overwintered mummy effect, S23

—canopy density, disease effect, S83

- downy mildew: azoxystrobin effect, S85; predictive models, S50

—Eutypa dieback, genetic analysis of strains, 884

- foliar and fruit diseases, fungicides, S95

— gray mold, defense induction, 197

-Phomopsis basicola, susceptibility time, S24

-phylloxera, root damage in vineyards, California, S47

-Pierce's disease, vector reduction by management, S62

Grapevine fanleaf virus, analysis amplified by RT-PCR, S55

Grapevine rupestris stem pitting associated virus, isolate diversity, S66

Grasses, prairies in Iowa, health and productivity, prescribed burning effect, $\mathrm{S} 106$

Grau, C. R., S15, S60, S106, S107

Graves, W. R., S51

Gray, L. E., S15

Greathouse, T. E., 861

Grebus, M. E., 53

Green, J. F., S9

Green, R., 272

Gremmeniella abietina, North American and European populations, allelic differences, S44

Greyerbiehl, J. A., S29

Griffith, M., S34

Grimm, C., S28

Grisham, M. P., S29, S30

Groome, P. C., S100

Gross, J. A., S66

Gross, P. L., S107

Grossmann, K., S40

Groth, J. V., S2, S5

Groundnut (see also Peanut)

-rosette, status in Kenya, S83

-rosette disease agents, spatiotemporal separation, 934

Groundnut rosette virus, on peanut, factors, S55

Grove, G., S30

Grumet, R., S79, S83

Grünwald, N. J., S30

Grybauskas, A. P., S30, S100

Gu, Y.-H., S50

Guan, J., S30, S105

Guaragna, M. A., S40, S48

Gubler, W. D., S8, S31

Gudmestad, N. C., S68

Guenthner, B. J., S66

Guest, C. A., S107

Guevara, M. G., S31

Guevara-González, R. G., 540

Guikema, J. A., S107

Gullino, M. L., 1169

Gundersheim, N. A., S48

Guo, B. Z., S31 
Gutierrez, H. E., S31

Gutierrez, W. A., S31

Guzmán, M., S85

Guzman, P., S71

Gwinn, K. D., S9, S84

Gyawali, C., S88

Gyenis, L., S31

Haber, S., S17, S31, S32, S61, S70

Hadidi, A., S71

Hagan, A. K., S32

Hagood, E. S., S101

Hall, M. R., S96

Hall, R., S54, S61, S83

Hall, W., S8

Halley, S., S106

Hamel, C., S25

Hamelin, R. C., 915, S12, S22, S44

Hamilton, S. L., S9

Hammer, T. H., S19

Hammerschmidt, R., 598, S29, S80, S86

Hammock, B. M., S82

Han, L., S32

Han, S. S., 928

Han, Y., S32

Handelsman, J., S66

Hanna, W. W., S85

Hansen, J. M., S32

Hanson, L. E., S32

Hanson, S. F., 480

Harakava, R., S33

Harder, D. E., 1214

Hardy, G., S17

Haring, M. A., 156, 1131

Harlton, C. H., S45

Harman, G. E., S86

Harper, K., 1015

Harrington, T. C., S90

Harris, L., S58

Harrison, J., S3

Hartman, C., S98

Hartman, G. L., 796

Hartung, J. S., S62

Hase, S., 1186

Hasegawa, H., S14

Hataya, T., 118

Hausbeck, M. K., S10, S43, S52, S65, S99, S100, S103

Haye, B., 197

Hayes, K., S63

Hayes, P. M., S15

Haynes, J. L., S60

Haynes, K. G., S46, S64

Hazanovsky, M., S78

$\mathrm{He}, \mathrm{C}$. Y., S33

Heath, M. C., S54

Hebbar, K. P., S33

Hein, G. L., 1182

Heist, E. P., S33, S94

Helicobasidium mompa, nucleotide sequence, detection, S58

Hemmes, D., S87

Henderson, D. M., S40

Hendson, M., 53, S46

Henkels, M. D., 1162

Henry, M. (Mexico), S33

Henry, M. J. (Calif.), 53

Henson, J. M., S23, S55

Herbicides, lactofen, soybean Sclerotinia stem rot suppressed by, 598

Herlaar, F., 156

Herlache, T. C., S33

Hess, D. E., S85

Hesterberg, D. L., S25

Heterobasidion annosum, on white fir, genetics in California, 546

Heterodera spp.

$-H$. glycines: esophageal gland secretory genes, method, S82; parasitism by fungus, 1193; soil texture and tillage relation, 844; on soybean, resistance deployment, S40; on soybean, tillage effect, 204

-H. schachtii: on cabbage, reproduction, S37; soil suppressiveness, survey, S84; on sugar beet, selection effect and variability, 68; on Swiss chard, soil suppressiveness, 434

-H. trifolii, populations, genetics and host specificity, S82

Hibi, T., S35

Hibiscus rosa-sinensis, witches' broom, in Brazil, $\mathrm{S} 100$

Hickey, K. D., S102

Hickman, Z., S34

Hidaka, S., S77

Hiebert, E., 701, S62, S83

Hiel, A. L., S85

Higgins, R. S., S107

Hilf, M. E., 336, S33

Hinckley, C. A., S85

Hindman, S., S86

Hinton, D. M., S27

Hirano, S. S., S34, S79

Hiruki, C., S82

Ho, G.-D., 673

Hobbs, H. A., S34

Hoffman, B., S34

Hofman, V., S106

Hogue, R., S44

Hoitink, H. A. J., S2, S42

Holbrook, C. C., S94

Holcomb, G. E., S94

Holcomb, M. A., S73

Holderness, M., 414

Hollmann, P. J., S34

Hollowell, J. E., S72

Holmes, G. J., 716

Holmstadt, J. J., S85

Holt, J., 934

Hong, C. X., S34

Hooker, D., S69

Hoover, R., S42

Hop stunt viroid, on citrus, cachexia and xyloporosis, 568

Hopkin, A., 915

Horita, M., S34

Horiuchi, S., S87

Horst, L. E., S42

Horst, R. K., 1126

Hou, Y. M., S71

Houghton, R. D., S63

Howard, R. J., S13, S22, S35, S82

Howell, C. R., S4, S32

Hoy, J. W., S8

Hsiang, T., S34, S54

Hu, J. S., S70

Huang, Z., S35

Huber, D. M., S107

Hudelson, B. D., S107

Hudyncia, J., S16

Huel, R., S56

Huet, H., 1022

Huettel, R. N., S52

Hughes, G., 487, 770, 1080, 1088, S52

Hughes, S. L., S67

Hughes, T. J., S106

Hulbert, S., S104

Humber, R. A., S52

Hunt, R. S., S35

Hussey, R. S., S82

Hwang, S. F., S13, S35, S82

Hyakumachi, M., 314

Hypersensitivity

-Arabidopsis thaliana to bacterial wilt, 673

— poplar to leaf rust, histology, 233

Ibanez, A. M., 851, S35, S59

Idris, A. M., 273, S91

Igarashi, S., S45
Iglesias, A., S35

Im, D. J., S40

Impatiens hawkeri, web blight, in New Guinea, S51

Ingels, C. A., S31

Inglis, D. A., S20

Inoue, H., S35

Ip, D. W., S48

Irelan, N. A., 884

Irey, M., 603

Irrigation

-moisture deficit stress, potato early dying, 782

-zoosporic fungi in systems, biological approaches controlled, S49

Irvine, J. E., S36

Isakeit, T., S35, S36

Ishiguro, K., S77

Ishimaru, C. A., S9, S44

Ismael, A. M., S23

Ito, A., 1186

Jabaji-Hare, S. H., S25, S81, S83

Jackson, E. L., 884

Jackson, L. E., 328

Jackson, T. A., S94

Jacobsen, B. J., S1, S17

Jaffee, B. A., 398, 712

Jaime-Garcia, R., S36

Jakobek, J. L., S36

James, D., S36

James, R. V., S21, S75

Janisiewicz, W. J., S18, S36

Janse, S., S50

Jara, C., S47

Jarret, R. L., S15

Jaunet, T. X., 320

Jaworski, A. J., S88

Jeandet, P., 298

Jeffers, S. N., S82, S88

Jeger, M. J., S27

Jellison, J., S99

Jenkins, J. C., S36

Jenner, C. E., S67

Jenns, A. E., S22

Ji, C., S36

Jiang, G., S14

Jijakli, M. H., S37, S42

Jin, R., S37

Jin, X., S85

Jin, Y., S89

Johnson, A. W., S18

Johnson, B. J., S1

Johnson, C. S., S37

Johnson, D. A., S76

Johnson, K. B., 974, S75

Johnson, L. B., S84

Johnson, S. J., S63

Johnson, S. V., S51

Johnsongrass mosaic virus, attenuated virulence, host-induced mutation, S32

Johnston, H. W., S24

Johnston, S., S100

Jomantiene, R., S102

Jones, A. L., 100, S37, S50, S51, S70

Jones, D. C., S51

Jones, J. B., 328, 646, 1044, S3, S53, S89

Jones, J. K., S36

Jones, P., S37

Jones, R. K., S21

Joppa, L. R., S74

Jordan, R., S40, S48

Juba, J., S52

Judelson, H. S., 754

Jurkonie, D. D., S37

Juzwik, J., S37, S38

Kadooka, C. Y., S78

Kageyama, K., 314

Kaiser, W. (Wash.), S40

Kaiser, W. J. (Germany), S44 
Kalvelyte, A., S102

Kamakura, T., S35

Kanematsu, S., S58, S77

Kang, S., S80

Kao, J., 707

Kaplan, I. B., S38

Kaplan, M., 68

Karanja, K., S99

Karasawa, A., 1186

Karasev, A. V., 336

Karsies, T., S38

Kasaai, M. R., S6, S38

Kassemeyer, H.-H., S70

Katan, J., 831

Katan, T., 623

Keel, C., S88

Keinath, A. P., S38, S42, S95

Kelemu, S., S38

Kelley, S. E., S38

Kemerait, R. C., Jr., S39

Kenerley, C. M., S4

Kenney, D. S., S39, S65

Kerber, E. R., 518

Kessel, G. J. T., 868

Khadhair, A.-H., S39

Khan, N. I., S39

Kharbanda, P. D., S43

Kilic, O., S105

Kim, D. H., 476

Kim, K. S., S21, S48, S93

Kim, M. K., S40

Kim, M.-S., S39

Kim, O. S., S40

Kim, S. H. (Canada), S34, S39

Kim, S. H. (Pa.), S39, S76

Kim, S. J., S76

Kim, Y. H., S40

Kimmins, F. M., 934, S55

Kinard, G. R., S40

Kindhart, J. D., S34

Kingston, G. A., S5

Kinkel, L. L., 131, S2

Kinloch, B. B., Jr., 192, 861

Kinscherf, T. G., S85

Kiraly, L., S16

Kirkpatrick, B. C., 962

Kirkpatrick, M. T., S95

Kirkpatrick, T. L., 613, S17, S94

Kistler, H. C., 407, 623, S32, S66

Kitajima, E. W., S27

Klein, J. D., S18

Klein-Gebbinck, H. W., S40

Kleinhofs, A., S15

Klittich, C. J. R., S40

Kloepper, J. W., S39, S40, S41, S49, S65, S67, S87, S89

Klopfenstein, N. B., S39

Kluepfel, D. A., S57

Knudsen, G. R., S4

Knudson, D. L., S9

Ko, W. H., S87

Kodama, M., 947

Koehle, H., S40

Koeller, W., S4

Koenning, S. R., S40

Köhl, J., 868

Kohmoto, K., 947

Koike, S. T., S8, S16, S40, S57

Koitabashi, M., S41

Koizumi, S., S3

Kokalis-Burelle, N., S41, S49, S66

Kolb, F. L., 343

Köller, W., S59

Kolmer, J. A., S41

Kolte, S. J., 1226

Kong, P., S67

Korkmaz, S., S33

Kormelink, R., 823

Kostansek, E. C., S63
Kosted, P. J., S27, S41

Kotan, R., S41

Kothera, R. T., S42

Koul, A., S58

Kousik, C. S., 1066, S42, S66

Kovacs, L. G., S32

Kramer, C. L., S24

Krause, C. R., S42

Kreuze, J. F., 462

Kristjansson, G., S44

Kroes, G. M. I. W., S64

Kronstad, J. W., S39

Kruger, W., S89

Kucharek, T. A., S39, S42, S62, S70

Kudrna, D., S15

Kuhajek, J. M., S96

Kukreja, K., S104

Kuldau, G., S102

Kummert, J., S42

Kuninaga, S., S11

Kuntze, L., 660

Kuramae-Izioka, E. E., S42

Kurtzweil, N. C., S60, S106, S107

Kushalappa, A. C., S4

Kusume, T., 1000

Kutcher, H. R., S42

Kuti, J. O., S31, S42, S55

Kuzyk, A., S56

Kwon, M.-O., 1144

Labbé, C., 728, S51

Labrosse, I., S43

Laccaria bicolor

-malate synthase, characterization, S5

- signal transduction gene, symbiosis regulated, S76

Lachner, J., S46

Laflamme, G., S44

Laliberte, J. F., S60, S76

Lamarque, C., 967

Lambalk, J. J. M., 156

Lambert, B., 197

Lambert, S., S33

LaMondia, J. A., S43

Lamour, K. H., S43

Lamppa, R. S., S107

Lamprecht, S., S43

Langan, K., S43

Lange, R. M., S43

Langham, M. A. C., S43

Langin, T., 1169

Langston, B. B., Jr., S81

Langston, D. B., Jr., S18

Lansdell, T. A., S44

Larkin, R. P., 1152, S26

Laroche, A., S44, S56

Larsen, R. C., S44

Latorre, B. A., S70

Laurans, F., 233

Laurer, U., 805

Lawrence, G. W., S51

Lawrey, J. D., S102

Lawrie, A. C., 392

Lax, A. R., 902

Leach, J., S4, S67, S104, S106, S107

Leal-Klevezas, D. S., S45

Leandro, L. F. S., S44

Leath, S., S3, S81

Leblanc, K., S44

Lebreton, L., 679

Leclerc-Potvin, C., S25, S83

Lecours, N., S44

Lee, B. C., S40

Lee, B. Y., 928

Lee, D. G., 928

Lee, F. N., S96

Lee, H. K., S44

Lee, I.-M., S60

Lee, K. W., S40
Lee, L., S45

Lee, M. (Ark.), S45

Lee, M. E. (Wis.), S60, S106

Lee, R. F., S13, S33

Lee, S. P., S34

Lee, S. W., 928

Lee, Y.-W., S1

Legard, D. E., S45, S52, S79, S86

Legendre, B. L., S29, S30

Legendre, L., 197

Legume, forage, luteoviruses of, characterization, 374

Lehman, J. S., S45, S83

Lei, L. P., S31

Leininger, T., S9

Lemanceau, P., 1073

Lemna pausicostata, apicidin phytotoxicity, $\mathrm{S} 1$

Lentil, root rot, seeding date and fungicide treatment, S35

Leonard, K. J., 131

Lepoivre, P., S37, S42

Leptosphaeria maculans

-in Brassica spp., resistance and linkage maps, S90

-on Brassica napus: isolate interaction, GUS reporter gene, S14; resistance, introgression, 1200

-on Brassica napus-B. juncea recombinant, pathogenicity, 169

Leroux, P., 967

Leroy, F., 380

Lesemann, D.-E., 148

Leslie, J. F., 182, S23, S60, S75

Letter to the editor, Polymyxa betae temporal buildup, model, 30

Lettuce

-bacterial leaf spot, biocontrol and nutrient effect, S77

- downy mildew, spatial analysis in California, S86

-Pythium, biocontrol with rhizosphere bacteria, S37

Lettuce infectious yellows virus

—defective RNAs, population, S67

-distribution and molecular variation, 707

Lettuce mosaic virus, coat protein gene, nucleotide sequencing, Brazil, S57

Leucostoma spp., on apple and stone fruit, in South Africa, S73

Leung, H. S104

Leverentz, B., S18, S36

Levesque, C. A., S45, S50

Levis, C., 967

Leviush, S., S78

Levy, M., S76

Leyva-Lopez, N. E., S45

Liang, H., S45

Lichens

-fungi of, phylogenetic analyses, S102

- fungi parasitic on, molecular data sets, S99

Liddell, C. M., S51

Limón, M. C., 254

Lin, Y., S61

Lindgren, P. B., S36

Lindgren, S., S14

Lindow, S. E., 353, S46

Line, R. F., 226, S15, S46

Lintott, L., S44

Liu, H.-Y., S57, S85

Liu, J. Q., S41

Liu, X. (Ariz.), S32

Liu, X.-Z. (China), S52

Liu, Y. (Mo.), S22

Liu, Y.-C. (N.Y.), 851, S46

Liu, Z., S46, S64

Livieratos, I. C., 1050

Livingston, W. H., S46

Llave, C., 1176

Lloyd, L., S106, S107

Loboda, A., S32 
LoBuglio, K., 967

Locke, J. C., S8

Lockhart, B. E. L., S46

Lombaers-van der Plas, C. H., 868

Lommel, S. A., S25

Longer, D., S67

LoParco, D. P., S73

Loper, J. E., 1073, 1162, S75

Lopez, F., 1200

López, M. M., 286

López-Abella, D., 1176

López-López, M. J., 286

Lorbeer, J. W., S48, S73

Loschinkohl, C., S46

Lotrakul, P., S47

Lotter, D. W., S47

Louie, R., S65

Louws, F. J., 328, S1, S29

Lu, B. C., S48

Lübberstedt, T., 660

Lucas, J.-M., 679

Lucas, P., 954

Ludwig, J. W., S1

Lukaesko, L. A., S60

Luke, H. H., 1125

Lumsden, R. D., S33

Lundeen, P., S87, S107

Lundquist, J. E., S47

Lunsford, J. N., S5

Luo, Y., S47

Luster, D. G., 374, S8, S47

Lycopersicon pennellii, hypersensitivity, Xanthomonas campestris, $\mathrm{S} 3$

Lydiate, D. J., S67

Lynch, R. E., S31

Lyngkjaer, M., S89

Lysobacter antibioticus, root colonization, biocontrol, S66

Ma, L., S12

Ma, W. L., S22

MacGuidwin, A. E., S106

MacHardy, W. E., S47

Macrophomina phaseolina, isolate characterization, AFLP technique, S80

Madden, L. V., 421, 555, 770, 1088, S24, S42, S78

Magee, J. B., S95

Magnaporthe grisea, on rice

- gene characterization and sequence analysis, S15

-gene identification, Leptosphaeria maculans comparison, S105

-infection peg formation, S35

-in Mali, Africa, genetics, S20

-strobilurin-sensitive mutants, $\mathrm{S} 4$

Magome, H., 136

Mahendra, S., 1022

Mahuku, G. S., S47

Maier, T., S82

Maimon, M., 456

Maize chlorotic mottle virus, cell-to-cell movement, S69

Maize necrotic streak virus, sequence homology, S65

Maize streak virus, genotype reaction, 695

Malaguti, S., S18

Maletta, M., S100

Mallett, K. I., S48

Malus spp., resistance to several diseases, North Carolina, S3

Mancino, C. F., S78

Mandrell, R. E., S14

Manfio, G. P., S48

Mango, malformation

— cause in Egypt, S60

-Fusarium subglutinans, GUS transformants, 456

Manion, P. D., S66

Manjunath, K. L., S13

Manning, T., S100

Manske, B., S66
Manteau, S., 197

Manuscript preparation, author's guide, 7

Marasas, W. F. O., 1126, S9, S75

Marcell, L. M., S48

Marchetti, M. A., S70

Marcone, C., 805

Margosan, D. A., S74

Marie-Jeanne, V., S70

Marín, D. H., S85

Marinho, V. L. A., S42

Mark, G. L., S48

Maroofi, A., S48

Maroon, C. J. M., S48

Marques, L. L. R., S48

Martin, D. P., 695

Martin, E. M., S48, S93

Martin, F. N., S49, S72

Martin, R. R., 124, S43, S76

Martínez, B., 1176

Martinez, C., 247

Martinez-Ochoa, N., S49, S65

Martínez-Soriano, J. P., S45

Martinez V., O., S80

Martinson, C. A., S83, S105

Mascagni, H. J., S78

Mascher, F., S49

Masiunas, J. B., S34

Masuta, C., 118

Matheron, M. E., S7, S49

Mathis, W. L., S49

Mathre, D. E., S4

Matsuda, I., S76

Matsumoto, N., S58

Matsumoto, T., 47

Matthews, P. W., S49

Mavrodi, D., S35

Mavrodieva, V. A., S33

Maxson, K. L., S50

Maxwell, D. P., 262, 480, S68

Mayhew, D. E., S79

Maynard, C. A., S45

Mayo, M. A., 1015

Mayorga, M. E., S28

Mayton, H., S50

Mazzola, M., 920, S50

McAlpin, C. E., S50, S80

McBride, J. R., S62

McComb, J., S17

McCormick, S. P., S2, S39

McDonald, B. A., 639

McDonald, G. I., S39

McDonald, M. R., S50

McElreath, S., S74

McEvoy, J. L., S85

McFadden-Smith, W., S50, S83

McGarvey, J. A., 1233

McGawley, E. C., S8

McGee, J. D., S106, S107

McGhee, G. C., S51

McGinn, M. E., S51

McGovern, R. J., S91

McGrath, M. T., S51, S100

McKellar, M. E., S21

McLaughlin, R. J., 1162

McLean, K. S., S51

McManus, P. S., 1127, S10

McMillan, R. T., Jr., S51

McMullen, M., S106

McNally, D., S51

McPherson, R. A., S58

McPherson, R. M., S51

McRoberts, N., S52

Medina-Mora, C. M., S52, S100

Mei, R., S87

Meijer, E. M. J., 868

Meinhardt, S. W., 293

Melampsora larici-populina, on poplar

- cover photo, March

- hypersensitivity, 233
Melcher, U., S10, S95

Melchinger, A. E., 660

Meloidogyne spp., on potato, diagnosis with DNA probes, 380

-M. hapla: genetic diversity in New York, S54; reproduction in tissue culture, S54; on sudangrass, cyanide evolution, S84

$-M$. incognita: on cotton, temperature effect, histopathology, 613; on pepper, resistance, temperature effect, S77; on tomato, amendments, aromatics, and rhizobacteria effects, S49

$-M$. javanica, on tomato, resistance induced by amino-butyric acid, 1138

Melouk, H. A., 653, S52

Melton, T. A., S31

Menarium, H., 281

Menge, J. A., S75, S87

Meredith, F., S88

Meronuck, R., S24

Mertely, J. C., S45, S52

Mes, J. J., 156, 1131

Meteorology, moisture prediction, neural network, S16

Metz, J. A. J., 495

Metzler, M. C., S56

Meunier, P., 298

Meyer, S. L. F., S52

Mezzalama, M., S52

Michailides, T. J., S21, S34, S82

Michelotti, E. L., S85

Michener, P. M., S52

Michler, C. H., S89

Microsphaeropsis, on Venturia inaequalis, mycoparasite, factors, $\mathrm{S} 6$

Migheli, Q., 1169

Milgroom, M. G., S46

Miller, J. D., 1028, S17

Miller, S. A., S2, S16, S19, S41, S53

Miller, S. S., S102

Mills, D. (Oreg.), S53

Mills, D. J. (Md), S53

Milus, E. A., S53

Mims, C. W., S53

Minsavage, G. V., 1044, S3, S53

Mirocha, C. J., S55

Mitchell, D. J., S79

Mitchell, F., S10, S95

Mitchell, T. K., S53

Mitkowski, N. A., S54

Miyagawa, H., S55

Mocz, G., S86

Model

- citrus tristeza virus, vectors and spatial dynamics, stochastic, 603

-fungal expansion and morphological components, computer simulation, S63

- Gaussian, disease foci of wheat head blight, 74

- gene-for-gene host parasite, 811

— pandemics of focal plant disease, 495

— potato cyst nematodes, infestation foci, 583

- spatial, strawberry leaf blight analysis, 421

- spatial scale and dispersion, 770

- surface wetness prediction, 668

- take-all of wheat, fungicide efficacy, 954

Moënne-Loccoz, Y., S49

Moline, H. E., S54, S100

Momol, E. A., S54

Momol, M. T., S20, S54

Monilinia spp.

-M. fructicola: antagonists to, selection, S54; cutinase, characterization, S82; on peach, vegetative compatibility groups, S23; on stone fruit mummies, survival, S34

-M. oxycocci, on cranberry, flower infection, cultivar resistance, 1127

-M. vaccinii-corymbosi: on blueberry, epidemiology in Georgia, S69; on blueberry, hyphae in flowers and fruits, S45; on Vaccinium, resistance, $\mathrm{S} 83$ 
Montano, H. G., S100

Moorman, F. E., S78

Moos, J., S106

Morant, M., S26, S54, S99

Moravec, B., S50

Moreira, M. A., 281

Morgante, M., 748

Mori, M., 385

Moriones, E., 1038

Morishita, H., 118

Morris, C. E., S77, S84

Morrison, R. H., 1084

Mould, M. J. R., S54

Mount, M. S., S100

Moyer, J. W., 575

Mpofu, S. I., S54

Mullahey, J. J., S84

Mulrooney, R. P., S101

Mundt, C. C., 64, 984, S26

Munkvold, G. P., 884, S104

Muñoz, F., S38

Murakami, H., S54

Murillo, I., 737

Muriuki, J. G., S55

Murphy, J. F., S67

Murphy, J. P., S81

Mycosphaerella graminicola, on wheat, resistance genes, S28

Mycotoxin

-aflatoxin: biosynthesis in corn kernels, amylase gene, 908; in corn, host resistance, 113

-beauvericin, duckling bioassay, S80

-Fusarium in corn ears, species interaction, 1028

- plant compounds inhibitory to, S86

-in Pyrenophora tritici-repentis, necrosis induction, 293

Myers, A. L., S27

Myers, L. D., S19

Myers, O., S47

Myrholm, C. L., S48

Myrothecium verrucaria, weed pathogens, molecular fingerprinting, S47

Myrta, A., 991

Nagahashi, G., S21, S55

Nagata, N., S78

Nagata, R. T., S19

Nagata, T., 823

Nahkla, M. K., S68

Naidu, R. A., 934, S55, S83

Nakaho, K., S55

Nakajima, H., 947

Nakazawa-Nasu, Y., 1186

Nameth, S. T., S26, S68

Naraghi-Arani, P., S55

Nash, D., S55

Nashaat, N. I., 1226

Navas-Castillo, J., 1038

Nawar, H. F., S42, S55

Nectria spp.

$-N$. coccinea, in beech, evaluation technique, S81

$-N$. galligena, gene transfer system, S76

$-N$. haematococca, on pea, pathogenicity gene cluster, S32

Neefus, C. D., S47

Neerium oleander, leaf scorch, cause, 53

Neimark, H., 805

Nelson, B. D., S105

Nelson, E. B., S21, S37

Nelson, M. R., 761

Nelson, R., S104

Nelson, T., S8

Nematicides, dichloropropene, row fumigation in Florida, S65

Neomycin phosphotransferase, detection in plants, S7

Nesmith, W. C., S33, S94

Nester, S. E., S8

Neuman, M. F., S38
Neumann, M. J., S56

Neumann, P., S81

Newman, M. (Ga.), S15

Newman, M. A. (Tenn.), S75

Niblett, C. L., S13

Nicholson, R. L., 272

Nickell, C. D., 59

Nicol, R. W., 1028

Nicole, M., 1200

Nieva, L. P., 64

Nishiguchi, M., 385

Nishimura, M., 118

Nishimura, N., S56

Nissinen, R. M., S56

Nitao, J. K., S52

Nitzsche, P., S100

Noh, J. H., S40

Norberg, E., S62

Norelli, J. L., S56

Norman, D. J., 646, S56

Norton, R. A., S36

Novacky, A., 1124

Ntahimpera, N., 555

Nuez, F., S35

Nutter, F. W., Jr., S30, S44, S56, S59, S83, S101, S105, S106

Nykiforuk, C. L., S56

Nyrop, J. P., 1104

Oak, S. W., S57

Oak, wilt, nitidulid association, S38

Oat

—microsatellite markers, S58

- powdery mildew, rice and barley chitinase gene genetically engineered, S80

- stem rust, gene $\mathrm{Pg} 10$ in resistance, 1214

Obermeier, C., S57, S85

Obituaries

-Carlyle Newton Clayton, 532

- Alvaro Santos Costa, 112

- Harry Ernest Duncan, 612

-Robert N. Goodman, 1124

- Teddy Theodore Hebert, 352

-Richard Malcolm Lister, 272

-Paul E. Nelson, 1126

- Harry Ernest Wheeler, 1125

Odontoglossum ringspot virus, detection using immuno-capillary zone electrophoresis, 522

Odvody, G. N., S35

O'Garro, L. W., S57

Ogata, D., S78

O'Gorman, D., S45

Ohr, H. D., S22

Ohtsu, Y., S58

Oidium sp., on poinsettia, temperature effect, S10

Oka, Y., 1138

Okada, I., 1186, S58

Okey, E. N., S57

Oku, T., S35

Olaya, G., S43, S64

Oliva, C. R., 840, S31

Oliveira, F. A., S57

Olivera, G., S72

Olsen, L., 851, S59

Olson, B. D., S101

Olson, S. M., S54

Olson, T. N., S39

O’Mara, J. K., S57

Omer, A. D., S47

Omer, M. A., S57

O'Neill, N. R., S3, S98, S99

Ong, C. A., 1022

Ong, K. L., S57

Onion

-Aspergillus niger and Fusarium sp. in seedlings, systemic, S73

-bacterial diseases, previous crop effect, S48

- shallot yellow stripe virus and Welsh onion yellow stripe virus, relation, 148
Onion yellow dwarf virus, type strains and virus relations, 148

Ophiosphaerella spp., new species on grass, S99

Ophiostoma complex, Ceratocystis and Leptographium comparison, $\mathrm{S} 9$

Ophiostoma spp.

-O. floccosum, serine proteinase production, cloning, S34

-O. piceae: genetics, in Canada, S26; transcribed spacers in, Canada, S39

-O. piliferum, on lodgepole pine logs, pigmented fungi spread prevention, S79

Oplinger, E. S., S106

Orchid, Rhizoctonia solani, mycorrhizal isolates, new anastomosis group, 942

Orellana, N., 286

Orobanche crenata, faba bean root extracts, germination effect, S31

Orum, T. V., 761

Osaki, H., S58

Osborne, L. E., S106

Osler, R., 894

Ospina-Giraldo, M. D., 308, S17

Ostrow, K. M., 273

Ostry, M. E., S31

Otani, H., 947

Otrosina, W. J., 546, S96

Oudemans, P. V., 218, S45, S83

Ouellet, T., 1028, S58

Overton, R., S96

Ozbek, A., S41

Paenibacillus sp., on cucumber, Fusarium wilt control, 92

Pair, S., S10, S95

Pal, N., S58

Pallás, V., 991

Palm, M. E., S99

Palmer, L. M., S48

Palukaitis, P., S38

Pan, S. Q., S58

Pan, Y.-B., S29, S30

Panaccione, D. G., S58

Panagrahi, S., S16, S106

Pandemic, focal plant disease model, 495

Panicum mosaic virus

- replicase-associated protein, S5

- satellite RNA, genetic diversity, S11

Panigrahi, S., 668

Pantoae agglomerans, herbicolin biosynthesis genes, plasposon mutagenesis, S44

Papaya ringspot virus, coat protein gene, diversity in Florida, S19

Paper mill sludge, raw and composted, root rot effect, S75

Pappu, H. R., S6, S15, S51, S58, S59, S83, S95

Pappu, S. S., S6, S59

Paquet, M., S59

Park, C. S., 92

Park, D.-S., S29

Park, J.-W., S62

Parker, D. M., S59

Parker, M., S59

Parkin, I. A., S67

Parks, R. L., S59

Parra, G. R., S77

Parsley

— powdery mildew, biocontrol, S41

-Septoria leaf blight, fungicides and disease prediction, S53

Parsnip, aster yellows phytoplasma, molecular characterization, S39

Parsons, C. E., S95

Pataky, J. K., S52

Patil, M. A., S60

Patil, S. S., S86

Paul, R. N., S1

Paulin, L., 462

Paulitz, T. C., 74, S10 
Paulsen, A. Q., S106

Pavoine, M. T., 533

Paximadis, M., 303

Paxson, L. K., S47

Pea, Aphanomyces root rot, Pseudomonas corrugata suppression, S65

Pea enation mosaic virus, wild-type and mutant RNAs, S73

Pea streak virus, satellite RNA, characterization, S44

Peach

-bacterial spot, Actigard evaluation, S11

- canker, Leucostoma, in South Africa, S74

—replant disorder, methyl iodide fumigation, S22

Peach mosaic virus, RT-PCR detection, S36

Peanut (see also Groundnut)

- azoxystrobin uptake and redistribution, S5

- early leaf spot, corn intercropping effect, S80

-leaf spot, temperature and wetness effect, 653

- leaf spot and stem rot, Dopple radar precipitation estimates, S32

_ pod rot, fungicides, North Carolina, S72

- soilborne pathogens, variety effect, S39

- stripe and mottle virus infection, seed lot testing, S94

-tomato spotted wilt virus, resistance, S95

- trypsin inhibitor gene, sequencing, S61

Peanut stripe virus, antigenic diversity, S6

Pear

-brown spot, host-specific toxins, 947

-fire blight: antagonistic mixtures for control, criteria, S75; nectar effect on microbial antagonists, 39; prohexadione-Ca effect, S18

—scab, fall chemical applications, S31

- stigma and hypanthium colonization, by bacteria, 1162

Pecan, scab

-fungicide program, S93

-leaf wetness period, S57

Pecina Q., V., S80

Pedersen, W. L., 796

Pederson, J., S106

Peever, T. L., 851, S59

Penaloza-Vazquez, A., S25

Peng, G., S59

Penicillium spp., fungicide sensitivity, postharvest, 716

Pennings, G. G. H., S86

Pennisetum glaucum, rust

-multiline population approach, S96

-resistance complexity through host intermating, 450

Pennypacker, B. W., 618, S59, S101

Pepper

-bacterial spot: biocontrol, S19; multiphasic analysis of strains in Caribbean and Central America, 328; mutation and aggressiveness, S42

—benzothiadiazole, control, yield, S66

- soilborne pathogens, soil treatments, S66

Pepper huasteco virus, on tobacco

- coat protein mutants, 540

-tomato, and pepper, synergism, S71

Percich, J. A., S24

Percifield, R. J., S106

Pereyra, S. A., S60

Perez, N. A. R., S42

Peronospora tabacina, on tobacco, gnotobiotic association, S33, S94

Peters, R. D., S60, S107

Petersen, M. A., S62

Petit-Paly, G., S27

Pettway, R. E., 623, S11, S66

Petunia, mosaic and other viruses, in Ohio, S68

Pfender, W. F., S60

Phaeocryptopus gaeumannii, on Douglas-fir, fungicide effect, $\mathrm{S} 14$

Phaeoisariopsis griseola, on bean, molecular diversity in Central America, S47

Phaseolus spp., bean golden mosaic virus, isolate variability in Brazil, 262
-P. vulgaris: anthracnose, resistant gene Co-6, 281; mosaic and rust resistance, S102; rhizobium, strain compatibility, S77; root rot, cultural practices in management, $\mathrm{S} 1$; suppression by soil aluminum, 47; white mold, resistance sources, S64

Phialophora spp., variants, osmotic potential, S23

-P. gregata: on soybean, cyst nematode relation, S106; on soybean, resistance using reciprocal grafting, 59; subspecies populations, molecular marker, S15

Philion, V., S11, S13, S20

Philip, E., S54, S99

Phoenix canariensis, Fusarium wilt, diagnosis, 407

Phomopsis spp.

-P. amaranthicola, on Amaranthus spp., biocontrol, S86

-P. longicolla, on soybean, molecular detection in seed, 796

-P. obscurans, on strawberry, spatial pattern analysis, 421

Phyllosphere, bacterial colonization, review, 353

Phytophthora spp.: on Fraser fir, in North Carolina, S6; on oil palm, DNA polymorphism, S3

-P. capsici: on cucurbits, populations in Michigan, S43; fungicides, Georgia, S18; mefenoxam insensitivity, in Georgia, S49; on pepper, acibenzolar-S-methyl effect, $\mathrm{S} 49$; on pepper, resistance factor, S87

-P. cinnamomi, survival, S17

$-P$. fragariae, on raspberry, Streptomyces interaction, biocontrol agent, S59

-P. glovera, on tobacco, molecular characterization, S72

$-P$. infestans: fungicide resistance, multiple loci, 754; herbarium specimens, S77; on nightshade, S19; pathogen inheritance, S50; pathotypes, Washington, S20; on potato and tomato, aggressiveness and competitive fitness, in France, 679; sporangium survival, S76; sporangium survival, solar radiation, S36; on tubers, temperature effect, S68; zoospores in soil, fungicide effect on germination, $\mathrm{S} 21$

$-P$. nicotianae, disease control with botanical extracts, S8

-P. parasitica: aluminum chelation effect, $\mathrm{S} 25$; on citrus, biocontrol with Pseudomonas putida, S75; DNA extraction, PCR amplification, S59

-P. sojae: pathotypes, Rps gene combination, $\mathrm{S} 104$; races, distribution in Arkansas, S94; on soybean, soil texture and tillage relation, 844; on soybean, tillage effect, 204

Phytoplasma

-localization in host plants and insect vectors, hybridization probes, 894

- phylogenetic groups, chromosome size, 805

— protein analysis, gel electrophoresis, S76

- strain characterization, DNA heteroduplex mobility, $\mathrm{S} 82$

Picard, K., 506

Pichia anomala, on apple, monitor in postharvest storage, S37

Pico, B., S35

Pierce, M. L., S60

Piercey-Normore, M. D., S101

Pilate, G., 233

Pine

- fusiform rust, defense mechanisms, S82

- jack and red, Armillaria root disease, stump removal, S48

- longleaf, root burns, cellular pathology, S96

- seedling root and shoot growth, bacterial amendments, S24

Pineapple, mealybug wilt, mealybug and virus association, S70

Pinkas, Y., 456

Pinnow, D. L., S94

Pintor-Toro, J. A., 254
Pinus spp.

$-P$. lambertiana, blister rust, virulence inheritance, 192

-P. monticola: blister rust, field resistance, S35; white pine blister rust, resistance major gene, 861

-P. strobus: blister rust, resistance, S89; rust, genetic structure of, in Canada, 915

Piquer, J., 286

Pirio, N., 298

Pirone, T. P., 564, 1125

Pittman, R. N., S94

Plante, D., S60, S76

Plasmodiophora brassicae

- on Chinese cabbage, inhibition by leafy daikon, S54

-on crucifers, spore surface disinfestation, 314

- detection with PCR polymers, soil and water, 392

-on turnip roots, cover photo, April

Pleiochaeta setosa, lupin, conidial germination, $\mathrm{S} 17$

Ploetz, R. C., S60

Plyler, T. R., 407

Podila, G. K., S5, S76

Podosphaera clandestina, cleistothecia, wind dispersal, S30

Poinsettia, powdery mildew, management, S99

Polston, J. E., 701, S91

Polymyxa betae, on sugar beet, temporal buildup model, letter to editor, 30

Pope, E. J., 942

Popenuck, T., 546

Poplar, Agrobacterium-mediated transformation, oxalic oxidate gene, S45

Poplawsky, A. R., S60, S61

Populus spp.

-leaf rust, hypersensitivity and histology, 233

- Septoria leaf spot and canker, biocontrol, S31

Porchas, M., S49

Porter, I. J., 392

Portmann, C. E., S39

Postharvest diseases, stone fruits, fludioxonil, S26

Postharvest pathology

- chitosan effect on pathogens, S38

- citrus green and blue mold, resistance to imazalil, 716

Potato

- bacterial ring rot, detection in core fluid, S53

-black scurf and common scab, chlorine disinfection, S24

- common pitted and netted scab, gene analysis, in Finland, 462

- common scab, thaxtomin effect, S1

- cyst nematode, infestation foci model, 583

- early blight, azoxystrobin for control, S75

- early dying, soil moisture and host resistance, 782

-fludioxonil for disease control, in Canada, S4

-Fusarium dry rot: biocontrol, S41; biocontrol with bacteria, $\mathrm{S} 67$

-Glomus and Rhizoctonia interaction, ultrastructure, S87

-late blight: data collection methods, prediction, S101; fungicide resistance, 754; integrated control and resistance, in Mexico, S30; isolates in France, 679 ; reaction classes in screening, S36; resistance gene, sequence analysis, S46; tuber resistance, S64

-new Carla virus, characteristics, S99

- paper mill sludge effect on disease, S75

- proteinase inhibitor, characteristics, 840

- root-knot nematodes, species diagnosis with DNA probes, 380

- sprouting, biocontrol by bacteria, S73

- tuber, aspartic protease, antifungal activity, S31

- tuber colonization by dry rot and sprout inhibiting bacteria, S69

- tuber treatment, chitosan and resistance, S29 
-Verticillium dahliae and Pratylenchus penetrans, synergism, S57

Potato latent carlavirus, characteristics, S29

Potato leafroll virus, detection, phage display libraries, fusion proteins, 1015

Potato virus $\mathrm{X}$, potato virus $\mathrm{Y}$

- comparison, resistance, S43

—resistance in segregating populations, S12

Potato virus $\mathrm{Y}$

- pepper isolate, transmission efficiency, mutations, 1176

- on potato and tobacco, in South Korea, S15

-on tobacco, resistance gene VA, 118

Powell, C. A., S61

Powell, J. F., S61

Powell, W. A., S45

Powelson, M. L., 782

Powers, K. S., S107

Powers, T. O., S107

Pozzer, L., 823

Pradhan, M., S61

Prakoso, B., S37

Price, J. F., S86

Price, L. D., S61

Prunus necrotic ringspot virus, molecular variability in isolates, 991

Prunus serotina, branch decay, cation nutrient dynamics, S18

Pryor, B. M., S61

Pseudomonas spp.: on pear stigmas and hypanthia, epiphytic colonization during bloom, 1162 ; rhizosphere competence, S63

-P. fluorescens: plow pan microcosms, biocontrol, S49; on wheat, population density and diacetylphloroglucinol, in rhizosphere, 470; in wheat rhizosphere, antibiotics, S63

-P. putida, flax wilt suppressed by, 1073

-P. solanacearum, on potato and tomato, chitosan effect, S19

-P. syringae: alginate production, regulation, $\mathrm{S} 25$; on bean phyllosphere, factors, S79; on Brassica, California, S16; ethylene production, Ralstonia comparison, 360; Gac regulon, genotype diversity, S85; leaf saprophyte, 353; putative repressor, purification, $\mathrm{S} 86$; on snap beans, gene differential effects, S34; on stone fruits, development factors, 962

Pseudozyma flocculosa, biocontrol fingerprinting, S12

Puccinia spp.

$-P$. andropogonis, on bluestem, environmental constraints, S5

$-P$ graminis: on oat, gene $P g 10$ resistance source, 1214; on ryegrass and tall fescue, modeling infection conditions, S60; on wheat, resistance gene Lr34, nonsuppression of resistance, 518

$-P$. recondita, on wheat, survival in southern Great Plains, S24

$-P$. striiformis, on barley, resistant recessive genes, 226

-P. substriata, on pearl millet, resistance and host intermating, 450

-P. triticina, on wheat: international collections, $\mathrm{S} 41$; molecular polymorphism, S41; virulence pattern in Nebraska, S69

Puckhaber, L. S., S32

Pueppke, S. G., 1124

Pumpkin, disease management, resistance and fungicides, $\mathrm{S} 25$

Punja, Z. K., S59, S79

Punshon, C., S61

Purcell, A. H., 53, S62

Purcifull, D. E., S62, S83

Pusey, P. L., 39, S62

Pyrenopeziza brassicae, on oilseed rape, in UK, forecasting, S24

Pyrenophora spp.

-P. teres, on barley, molecular genetic marker identification, 176
- P. tritici-repentis, on wheat: interaction characterization, review, 444; necrosis-inducing toxin, genetic analysis, 293; PCR for detection, S5; races in U.S. Great Plains, S2

Pyricularia spp.

-P. grisea: on rice, myb genes, molecular cloning, S45; on ryegrass, US isolates, S80; on St. Augustinegrass, silicon effect, S19

-P. oryzae, on rice, leaf $\mathrm{CO}_{2}$ exchange, 789

Pythium spp.: antagonists, isolation and characterization, S20; Phytophthora spp. comparison, molecular phylogeny and evolution, S45; suppressive soils, bacterial communities, molecular characterization, S21

-P. aphanidermatum: azoxystrobin sensitivity, S43; isolate aggressiveness, mefenoxam effect, S59

$-P$. oligandrum, mycoparasite, soilborne pathogen interaction, 506

Qi, M., S62, S87

Qin, X., S62

Qiu, W. P., 575, S62

Quail, A., S45

Quan, S., S63

Quinn, J. A., S63

Raaijmakers, J. M. (Wash.), 470, S35, S63

Raaijmakers, J. M. (Netherlands), S20, S27

Raccah, B., S79

Rademacher, W., S18, S63

Rademaker, J. L. W., 328

Raffel, S. J., S66

Ragozzino, A., 805

Raina, R., S28

Rajkovska, V., S64

Ralstonia solanacearum

-on Arabidopsis thaliana, resistance, hypersensitivity, 673

- ethylene production, Pseudomonas comparison, 360

— siderophore gene, search, S7

-on tomato: population dynamics, S34; race 1 in Taiwan, 320; resistance and spatial-temporal analysis, 1233; virulence factors, S55

Ramanjulu, V., S64

Ramos, P. L., 540

Ramundo, B. A., S16, S64

Rand, R. E., S75

Randles, J. W., 877

Rashid, K. Y., S64

Rasmussen, J. B., S64, S105

Rasmussen, S. L., 476

Rasmusson, D. C., S24

Raspberry bushy dwarf virus, sequence comparison of strains, S76

Rathwell, P. J., S95

Rauyaree, P., S64

Reanwarakorn, K., 568

Recorbet, G., 1073

Reddy, B. J. D., S65

Reddy, M. S., S24, S39, S65, S67, S87, S89

Redinbaugh, M. G., S65

Reeleder, R. D., S65

Reich, R. M., S47

Reid, K. K., S79

Reid, L. M., 1028

Reid, T. C., S65

Reilley, A. A., S9

Rekah, Y., 831

Renard, M., 169, 1200

Resende, R. de O., 823

Resendiz, R., S56

Resistance

- barley to covered smut, PCR detection, 212

- barley to stripe rust, recessive genes, 226

-bean to anthracnose, resistance gene, 281

-Brassica juncea to white rust, 1226

- Brassica napus to Leptosphaeria maculans, cytology and introgression, 1200
- corn to sugarcane mosaic virus, 660

- cranberry to Monilinia oxycocci, 1127

- oat to stem rust, gene $\mathrm{Pg} 10$ usefulness, 1214

-oilseed rape to blackleg, 169

— pearl millet to rust, intermating, 450

-Penicillium spp. to imazalil, 716

- pepper to bacterial spot, major genes, 1066

- rice to bacterial blight, in Nepal, 687

-rice to rice tungro spherical virus, near immunity, 1022

- soybean to brown stem rot, reciprocal grafting, 59

- sweet potato to sweet potato feathery mottle virus, 385

- tomato to root-knot nematode, induction, 1138

-white pine to blister rust, major gene, 861

Rette, F. J., S63

Retzlaff, G., S40

Reviewers, acknowledgment of, 4

Rey, M. E. C., 303

Rey, P., 506

Reynoird, J.-P., S56

Reynoutria sachalinensis, bioprotectant, for ornamental plants, $\mathrm{S} 81$

Rezende, J. A. M., S27

Rhizoctonia spp.: binucleate, carboxin resistance gene transformation, S105; on Euphorbia and Centaurea spp., phylogenetic comparisons in USA and Eurasia, S55

$-R$. leguminicola, reclassification as an ascomycete, $\mathrm{S} 51$

-R. solani: anastomosis group $13, \mathrm{~S} 11$; anastomosis group 3, detection, S44; on bean, tolerance in Dominican Republic, S91; on Echinacea angustifolia, damping-off, S13; fatty acid profiles, in isolates AG-4 and AG-7, S5; inhibition by apple roots, 920; on orchid, mycorrhizal isolate of, anastomosis group, 942; on potato and tobacco, anastomosis group 3 subgroup, S12; on radish, fungicides, S16; on rice, azoxystrobin sensitivity, $\mathrm{S} 64$; on rice, populations in Côte d'Ivoire, 414; on tall fescue, irrigation and fungicide effect, $\mathrm{S} 71$

Rhizosphere, fatty acid methyl ester analysis in, S57

Rhodosporidium toruloides, on barley, leaf adhesion, S10

Rhynchosporium secalis

—on barley, seed assay, S44

- genetic structure, Australia, 639

Rice

-bacterial blight: $\mathrm{CO}_{2}$ exchange, 789; genotypic and pathotypic diversity in Nepal, 687; primary disease gradients, 64; strain distribution in Korea, 928

-blast: gene identification, early infection, S64; genes and chemical treatments, S62; "lineageinclusion" strategy in breeding, S76; resistance components, silicon, S70; resistance in mixtures, S3

- disease resistance, candidate gene mapping, S104

-false smut, in Arkansas, S96

- head blight and toxins, S1

- kernel smut, resistance, S96

- phospholipase D, gene cloning and characterization, S107

— sheath blight: fungicide in Arkansas, S95; population characterization in Côte d'Ivoire, 414

Rice tungro spherical virus, replicase-mediated resistance strategy, 1022

Rich, J. R., S54

Richardson, E. A., S53

Richardson, M. D., S77

Rideau, M., S27

Ried, C. L., S33

Riedel, R. M., 840

Riegel, C., S65

Riggs, R. D., 1193, S77, S82

Riley, T., S29 
Rimelspach, J. R., S26

Rimelspach, J. W., S46

Rimmer, S. R., S90

Rinker, D., S61

Risius, M. L., 618, S59, S101

Ristaino, J. B., S10, S77

Ritchie, D. F., 532, 1066, S42, S53, S66

Rivera, A., S30

Rivera-Bustamante, R. F., 540

Rivera-C., J. M., S83

Robb, J., S74

Roberts, D., S26, S101

Roberts, P. D., S79, S84

Roberts, R. G., 1162

Roberts, S., 754

Robinson, D. J., 934, S55

Rodriguez, M. X., S38

Rodríguez-Kábana, R., S17, S39, S41, S49, S65

Roemmelt, S., S63

Rogers, S. O., S12

Romaine, C. P., 308

Romero, A. M., S66

Ronald, P. S., S66

Rondon, M. R., S66

Roossinck, M. J., S11

Rosa, V. E., Jr., S42

Rosato, Y. B., S48

Rose, M. S., S79

Rosell, R. C., 239

Rosewich, U. L., 623, S11, S66

Ross, W. J., S95, S96

Rossing, W. A. H., 789

Rosskopf, E. N., S41, S66

Rotem, Y., 631

Rothrock, C. S., 613, S53, S95

Roussel, S., 1200

Roux, C., 247

Rowe, R. C., S57

Rowhani, A., S55, S66, S89

Rowley, K. B., S86

Roy, R., S65

Royse, D. J., 308, S17

Rubin, B. D., S66

Rubio, L., 707, S67

Rubio, O., S30

Rudolph, K., 591

Rupe, J. C., S67, S93, S94, S95, S96

Rush, C. M., S45

Rusholme, R. L., S67

Russell, B. W., S53

Russin, J. S., 113, 902, S28, S31

Russin, S. J., S78

Russo, A. J., 374

Ryba-White, M., S67

Rybicki, E. P., 695

Ryder, E. J., S57

Ryu, C. M., S65, S67, S89

Sabaratnam, S., S67

Sabatini, E., S18

Sadfi Zouaoui, N., S67

Sahin, F., S19, S41

Saito, M., 1000

Sakthivel, N., S67

Salas, B., S68

Salati, R., S68

Salicylic acid

—plant defense response, S27

-resistance induced in tomato, 722

Salmonella enterica, on alfalfa sprout, interaction, S14

Salomon, R., S70

Samac, D. A., S107

Sams, C. E., S18, S93

Sanchez, J., S3

Sánchez-Campos, S., 1038

Sanchez-Cuevas, M. C., S68

Sanders, F. H., S81, S96

Sanderson, P. G., S68
Sandlin, C., S91

Sanogo, S., S68, S107

San Segundo, B., 737

Saparno, A., S58

Satou, M., S87

Saunders, S. R., 53, S62

Savage, A. K., S85

Savard, M., 1028

Savelle, A. T., S69

Sawchyn, K., S8

Sayler, R. J., 962

Sayre, K. D., S52

Scatella stagnalis, vector for Thielaviopsis basicola, on corn-salad, 476

Schaad, N. W., S8, S68

Schaafsma, A. W., 1028, S69

Schardl, C. L., S33, S58, S94

Schaupmeyer, C., S4

Scheets, K., S69

Schell, M. A., 1233

Scherm, H., S23, S69

Schilder, A. M. C., S69

Schiller, A., S107

Schimelfenig, J., S69

Schisler, D. A., S39, S69, S73

Schlarbaum, S., S74

Schlueter, K. O., S57

Schmitthenner, A. F., S93

Schnabel, E. L., 100, S70

Schnabel, G., 100, S70

Schneider, M., 328

Schneider, R. W., S11

Schneider, S., S70

Schoelz, J. E., S16, S71

Schoeny, A., 954

Scholthof, H. B., S20, S62

Scholthof, K.-B. G., S5, S11, S45

Schomaker, C. H., 583

Schulthess, F., S70

Schulze, D. G., S107

Sclerotinia spp., ribosomal DNA restriction site variation, $\mathrm{S} 107$

-S. homoeocarpa, on turf, taxonomic clarification, S61

$-S$. minor, on peanut, infection cushions, resistance, S52

-S. sclerotiorum: on bean, calcium effect, S107; on bean and cabbage, cutinase, S59; biocontrol with Coniothyrium minitans, 141; on canola, fungicides, S42; on carrot, postharvest effect, S29; on soybean, cultivar response, environmental sensitivity, 618; on soybean, resistance and pigment relation, $\mathrm{S} 87$; on soybean, suppression by lactofen herbicide, 598

Sclerotium rolfsii, sclerotium production, on paper, S11

Scott, D. B., S58

Scott, E., S70

Scott, R. A., S43

Seaman, W. L., 74

Sears, J. L., S57, S85

Sechler, A., S68

Secor, G. A., S68

Seebold, K. W., S70

Seem, R. C., S6, S23, S25, S70

Seemüller, E., 805

Seguin-Swartz, G., S14

Segura, J., S33

Seifers, D., S32, S70

Semancik, J. S., 568

Semer, C., S42

Septoria spp.

-S. musiva, on Populus, resistance screening, S74

- S. tritici, on wheat, cytology, S22

Sether, D. M., S70

Settle, D. M., S71

Sewall, T., S53

Sforza, P. M., S101

Shababi, M., S71
Shabana, Y. M., S71

Shackel, K. A., 962

Shah, D. A., S71

Shallot yellow stripe virus, on onion, characterization, 148

Shamloul, A. M., S71

Shamoun, S. F., S34, S71

Shaner, G., 272, 343

Sharp, L. P., S71

Sharpe, A. G., S67

Shaw, L. N., S65

Shaw, R. S., S102

She, Y., S32, S70

Shearer, B., S17

Shelby, R. A., S41, S66

Shelton, J., S57

Shelton, K. L., S95

Shen, Y., S86

Sherwood, J. E., 212, S27, S41

Sherwood, J. L., S19

Shetty, K. G., S72

Shew, B., S72, S80

Shew, H. D., S12, S25, S72

Shier, W. T., S1

Shim, W. B., S72

Shin, Y. C., 92

Shinners, T. C., S72

Shishido, Y., S54

Shishkoff, N., S102

Shokes, F. M., S94

Sholberg, P. L., S72

Shortle, W., S99

Shtienberg, D., 831

Sikaroodi, M., S102

Silveira, K. G., S107

Sim, J., S72, S73

Simmons, J. A., S54

Simone, G. W., 407, S62

Simons, S. A., 414

Sims, A. L., S60

Sims, J. J., S22

Singh, P. (Japan), 947

Singh, P. P. (Korea), 92

Singh, U. S., 1226

Sinisterra, X. H., 701

Sipes, B., S37, S78

Sirois, K. L., S73

Sivamani, E., 1022

Sivan, S., S78

Skaf, J. S., S73

Skalbeck, T. C., S38

Slack, S. A., S12

Slaughter, G., 546

Slawecki, R. A., S88

Slininger, P. J., S39, S69, S73

Slippers, B., S73

Smart, C. D., S50

Smilanick, J. L., S8, S74

Smit, L., S74

Smit, W. A., S73, S74

Smith, B. J., S15, S95

Smith, D. R., S74, S90

Smith, H., S2

Smith, J. E., S12

Smith, K. P., S24

Smith, O. P., 374

Smith, V. L., S43

Smolik, J. D., S43

Snider, C. S., S34

Sniezko, R. A., 861

Soika, E., S78

Soika, M. D., S78

Soil, binding, basidiomycete, L-fucose determinants, S11

Solanum viarum, biocontrol with bacteria, S84

Solarization, tomato and pepper diseases, management, S41

Somda, I., 169

Somers, D. (Minn.), S80 
Somers, D. J. (Canada), S90

Sonoda, S., 385

Soo, H. M., S58

Soong, J., 707

Sorensen, D., S74

Soria, C., 1038

Souza, N. L., S42

Soybean

-biocontrol agents in canopy, environmental factors, S106

-brown stem rot: nematode relation, tillage effect, 204; resistance using reciprocal grafting, 59; soil texture and tillage relation, 844

— cyst nematode: biocontrol agents, S77; chemosensory receptor gene, S87; corn, fallow, and cropping sequences, S56; fungal associations, antagonism, S52; in Ohio, 840; soil pH and population density, S106

—disease syndrome, Fusarium root colonization, S47

-Fusarium solani and Heterodera glycines interaction, cultivar resistance, S96

—glucan elicitor, trypsin inhibitor, S29

— green stem syndrome, in Midwest, S106

-Phomopsis seed decay, molecular detection, 796

—Pythium ultimum, soil flooding effect, S95

-root rot, chloride salt association, S93

- Sclerotinia stem rot: lactofen herbicide treatment, 598; regional prevalence, $\mathrm{S} 85$

—seed production, Arkansas, S67

—stem rot: resistance, SSR markers, S104; Sporidesmium sclerotivorum for biocontrol, S105

- sudden death syndrome: Fusarium solani in soil, S93; phosphate and potassium effect, S107

— sudden death syndrome and stem rot, lactofen treatment, S68

- top dieback, in Iowa, S107

— virus, outbreak in South Dakota, S43

-white mold, agronomic management, S59; cultivar response and environmental sensitivity, 618; row spacing in management, S101

Soybean dwarf virus

—strain genome comparison, S77

-virions, cover photo, May

Soybean mosaic virus

— cultivar resistance, ultrasound, S93

-Korean isolates, nucleotide sequence, S40

Soybean severe stunt virus, differential hybridization analysis, $\mathrm{S} 98$

Spaine, P., S74

Sparks, R. B., S105

Speakman, J. B., S63

Specht, J. E., S104

Spellman, M. R., S101

Sphaeropsis sapinea, on conifers, aggressiveness variation, S7

Sphaerotheca spp.

-S. fuliginea, on cucumber, ultrastructure, 728

$-S$. fusca, on cucumber cotyledons, cover photo, August

Spiegel, Y., 1138

Spiewak, S. L., S88

Spiraea spp., yellow leafspot, aphid-transmitted virus, S46

Spiroplasma citri, movement in vector, 1144

Spletzer, M. E., 722

Sporisorium reilianum, on corn, development in shoot apex, 247

Spruce

—winter injury, freezing cycles, S46

—wood decomposition, S99

Squash leaf curl virus

-bean calico mosaic virus affiliation, characterization, 273

-in whitefly vector, 239

Stachybotrys elegans

-mycoparasite on Rhizoctonia solani, acetylglucosaminidase, $\mathrm{S} 81$

- species-specific marker, S83
Stack, R. W., S32, S74

Stagonospora nodorum on wheat

—epidemic model, S3

- seed transmission, S71

Stall, R. E., 328, 646, 1044, S3, S53

Stammler, G., S63

Standing, K., S32, S70

Stanghellini, M. E., 476

Staniulis, J., S102

Stankiewicz, A., S74

Stanosz, G. R., S7, S74, S90

Stanosz, J. C., S74

Starmer, W. T., S12

St-Arnaud, M., S25, S81

Stavely, J. R., S102

Steadman, J. R., S91, S104, S107

Stebbins, T. S., S75

Steddom, K. C., S75

Steenkamp, E. T., S75

Steffens, P., 148

Steffenson, B. J., 176

Steimel, J. P., S90

Stemphylium spp.

$-S$. botryosum, on spinach, new in California, S40

- S. vesicarium: on pear, host-specific toxins, purification, 947; on tomato and pear leaves, cover photo, October

Stenger, D. C., 273, 1182

Stenlund, D. L., S37

Stenotrophomonas maltophilia

-leaf spot, biocontrol, 817

-leaf spot suppression in tall fescue, chitinase role, $\mathrm{S} 108$

- Rhizoctonia solani controlled by, chitin, S108

-on tall fescue, colonization spatial pattern, S105

Stephenson, M. G., S58

Stevenson, K. L., S57

Stevenson, W. R., S21, S75

Stewart, D. W., 1028

Stiles, C. M., 218

Stipanovic, R. D., S32

Stockwell, V. O., 1162, S75

Stone, A. G., S75

Stone, A. L., 374

St-Pierre, C. A., S17

St-Pierre, R. G., S66

Strawberry

- anthracnose, splash dispersal of conidia, 555

-black rot, Rhizoctonia and Pythium, S1

-Botrytis fruit rot: plant sanitation and yield, S52; row spacing and yield, S45

- Botrytis latent infection, monoclonal antibody assessment, $\mathrm{S} 4$

— crown rot, oversummer survival, in Florida, S79

- fruit, blossom, and foliar blights, California, S8

- fruit disease, epidemics in Florida, S86

-leaf blight, spatial pattern analysis, 421

- leaf blight and leaf spot, analysis of association, S78

-mycorrhizae, use in production, S29

-Phytophthora crown rot, resistance, screening, S9

- Pythium and Rhizoctonia, in California, S49

- Verticillium wilt, management by rotation, S72

Strawberry mild yellow edge virus, aphid transmission, S43

Streptomyces spp

-on cucumber, Fusarium wilt control, 92

-on potato, phylogenetic gene analysis, 462

Strickler, P., S56

Striga hermonthica, Pennisetum infection, S85

Strobel, G. C., S1

Stromberg, E. L., S101

Stromberg, K. D., 131

Stummer, B., S70

Subbarao, K. V., 1218, S7, S72, S86

Subrahmanyam, P., 934, S55

Sugar beet
-Aphanomyces damping-off, oospore concentration, S104

-bean necrotic yellow vein virus, rhizomania, 1000

-Cercospora leaf spot, biocontrol, S17

- cyst nematode, selection effect and genetic variability, 68

- Polymyxa betae, model for buildup, letter to editor, 30

—virus yellows complex, severity and resistance, S85

Sugarcane

—nematodes, microplot in Louisiana, S8

-ratoon stunting: in Florida, S17; hot water treatment and resistance, $\mathrm{S} 36$

-yellow leaf syndrome: luteovirus association, S29; yield and juice quality, S30

Sugarcane mosaic virus, on corn, resistance, loci mapping, 660

Sugarcane striate mosaic virus, identification, partial characterization, 877

Sugar, D., 1162

Sullivan, T. A., S36

Sulzinski, M. A., S76

Summerell, B. A., S56

Sumner, D. R., S18

Sun, P., 811

Sun, X., S29

Sundaram, S., S76

Sunseri, M. A., S76

Suomalainen, S., 462

Sutton, D. K., S47

Sutton, T. B., 532, S3, S85

Sutula, C. L., S7, S86

Suzuki, H., S76

Svircev, A. M., S27

Swart, W. J., S8

Sweat, T. A., S107

Sweet potato chlorotic stunt virus, whitefly transmission, $\mathrm{S} 73$

Sweet potato feathery mottle virus, in transgenic plants, resistance and coat protein gene, 385

Sweet potato leaf curl virus, nucleotide sequence and phylogeny, S47

Sy, A. A., 414

Sycamore, dieback, in southeastern USA, S9

Symons, R. H., 894

Symposia: Sampling for decision making in crop loss assessment and pest management -introduction, 1080

—plant disease incidence, 1088

- precision IPM, map as an objective, 1112

— seed health testing, 1084

-time and resource investment, 1104

Sztejnberg, A., 631

Tai, P. Y. P., S17

Takahashi, T., 47, 136

Tamada, T., 1000

Tamburic-Ilincic, L., S69

Tammen, J. F., 1126

Tampo, H., S76

Tanaka, M., S76

Tanguay, P., S76

Tapiero, A. L., S76

Tapsoda, H., 450

Tattar, T. A., S100

Taylor, N. J., 840

Taylor, S. M., S76

Teaching, tropical interdisciplinary course, S78

Teasdale, J. R., S53

Tedford, E., S43, S64

Tekauz, A., 840

Telford, E. B., S45

Tellez, M. R., S94

Tenzer, I., 748

Teplitski, M. I., S17

Terauchi, H., S77

Testerink, C. S., 1131

Teviotdale, B. L., S46 
Tewari, J. P., S44, S72

Thielaviopsis basicola

- aluminum chelation effect, S25

-on cotton, temperature effect, histopathology, 613

-on Valerianella locusta, fly vectors, 476

Thies, J. A., S77

Thiesse, B., S96

Thomas, C. E., S38

Thomashow, L. S., S35, S63

Thompson, I. A., S107

Tian, H., S77

Tian, T., S67

Tietjen, W., S100

Tiffany, L. H., S105

Tillandsia recurvata, sodium bicarbonate for control, S94

Tilletia spp.: life cycle, fungal pheromone-related compounds and inhibitions, S41; on wheat, molecular markers, S44

-T. indica: teliospore survival, Montana, S4; on wheat, axenic culture, S8

Tilletiopsis spp., hydrolytic enymes and antibiotic production, S79

Timmer, L. W., 851, S35, S59

Timper, P., 1193

Tirilly, Y., 506

Tisserat, N. A., S71

Tobacco

-Agrobacterium vitis, hypersensitivity, S33

-blue mold: fungicide summary, S98; systemic resistance, PGPR testing, S89

-leaf curl, phytoreovirus, South Africa, 303

—pathogen-inducible myb1 promoter, S87

- pepper huasteco virus on, coat protein mutants, 540

- potato virus Y: hypersensitivity, S25; resistance, 118

- Pseudomonas syringae, transformant effect on lesions, S2

-Pythium root rot, greenhouse transplants, S31

- spotted wilt, thrip distribution in Georgia, S51

- tomato mottle virus, modified coat protein, 701

Tobacco mosaic virus, replicase dissection, implications, S18

Todd, J. W., S6, S94, S95

Tomato

- bacterial diseases of, organic amendment and botanical aromatic effect, S49

-bacterial spot: biocontrol, S19; compost water extract effect, S2; multiphasic analysis of strains in Caribbean and Central America, 328

-bacterial wilt, race 1 in Taiwan, 320

-crown gall, biocontrol, dose response relation, 974

- early blight: anthracnose, and powdery mildew, azoxystrobin and chlorothalonil effect on, S100; rhizobacterial role, S87; salicylic acid induces resistance, 722

- enchytraeids and nematophagous fungi, in fields, 398, 712

— foliar disease, management, S53

-Fusarium crown and root rot: distribution and time in space, 831 ; population genetics, 623

-Fusarium wilt, biocontrol by nonpathogenic species, dose response, 1152

-late blight, isolates in France, 679

—nematodes, amendment effect, S10

- powdery mildew: chlorothalonil effect, S51; greenhouse, growth chamber, and field comparison, S12; host range and resistance, S43

- Pseudomonas syringae, transformant effect on disease, S2

-Ralstonia solanacearum, resistance and spatialtemporal analysis, 1233

-Ralstonia solanacearum and Meloidogyne arenaria on, suppressive soils, S54

—rishitin accumulation, gray mold resistance, S14

-root-knot nematode: local and systemic resistance, induction, 1138; organic amendments and natural chemicals, control, S41 -root-knot and fungal pathogens, biocontrol tactics, S40

—-soilborne microbes, soil amendment effects, S54

—soilborne pathogens, soil treatments, S66

-wilt, virulence and pathogenicity in mutant of Fusarium, 1131

Tomato bushy stunt virus

-on greenhouse-grown tomato, S85

-lettuce dieback association, in California, S57

-ribonucleoprotein complex, isolation, S20

-RNA, viral factors, S62

Tomato mosaic virus, detection in glacial ice, S12

Tomato mottle virus, on tobacco, coat protein transformation, 701

Tomato spotted wilt virus

-on Anthurium, bacterial blight symptom similarity, S78

—in peanut, resistance, S94

-on tobacco, Actigard and Admire effects, S58

- TSWV N gene-derived resistance, genome reassortment, 575

Tomato yellow leaf curl virus

- detection in Florida, S91

_-displacement in epidemic in Spain, 1038

- molecular epidemiology, in Dominican Republic, S68

Toojinda, T., S15

Tooley, P. W., S102

Torbert, K., S80

Torrance, L., 1015

Torres-Jerez, I., 239, S91

Torzilli, A. P., S102

Tosun, N., S20

Toth, R. L., 1015

Toussaint, V., S77

Toussoun, T. A., 1126

Toxins, necrosis-inducing, Pyrenophora tritici-repentis on wheat, 444

Toxoptera spp., citrus tristeza virus vector, stochastic model, 603

-T. citricida: on citrus, cover photo, June; on citrus, vector for tristeza virus, 487

Trail, F., S3, S86

Traquair, J. A., S67

Tredway, L. P., S77

Trees, disease and growth rate relation, hardwood forest, S66

Tremblay, M., S10

Trese, A. T., S77

Treutter, D., S63

Trevors, J. T., S8

Trichoderma spp.

$-T$. harzianum: antifungal activity, transformants with chitinase, overexpression, 254; biocontrol strains, molecular analysis, 308; on mushroom, biotype for, S3; on mushroom, survival after heat treatments, S61; rice sheath blight control, bioassay, S86; transformation, biocontrol, S4

-T. koningii, antibiotic production, S32

-T. stromaticum, Crinipellis perniciosa controlled by, formulation, S33

-T. virens: on cotton, phytoalexin elicitation, $\mathrm{S} 32$; extracellular proteinase, gene encoding, S4

Trichosanthes dioptera, potexvirus from, properties, S62

Trifolium spp., phyllody and dwarf, phytoplasma association, Lithuania, S102

Trout Groves, C., S77

Tsror, L., S78

Tsuchiya, K., S34

Tsushima, S., S54

Tubajika, K. M., S78

Tuinstra, M. R., S64

Tuori, R. P., 444

Turechek, W. W., 421, S78

Turfgrass

-age effect on gray leaf spot of tall fescue, S78

—dollar spot, measurement methods, S26
- fungal diseases, compost soil amendment effect, S46

- snow mold, antifreeze activity, S34

Turina, M., S5

Turini, T. A., S46

Turkington, T. K., S44

Turnbull, G. D., S35, S82

Turnip mosaic virus

- genetics in Brassica, S67

-helper component protein, purification, 564

-infection inhibits host translation, S60

Tylka, G. L., 204, 844, S56

Uchida, J., S78

Uchida, R. S., S78

Uchino, H., 1000

Uddin, W., S78, S80

Ullah, Z., S79, S83

Ullich, M. S., 360

Ulocladium atrum, biocontrol of Botrytis, 868

Uncinula necator

-on grape: host response, S25; perennation in

Washington, S30

-isolate matings, S70

Undersander, D. J., S107

Upchurch, R. G., S79

Uphoff, M. D., S87

Upper, C. D., S34, S79

Upton, C., S36

Ureña-Padilla, A., S79

Urmeev, F. I., S28

Uromyces appendiculatus, on bean, African and

American isolate comparison, S91

Urquhart, E. J., S79

Urs, R. R., S79, S84

Ustilago spp.

$-U$. hordei: on barley, PCR detection, 212; pheromone analogs, seed treatment, S27

-U. maydis: calcineurin effect on dimorphism and pathogenicity, S22; on corn, $u b c$ genes, transduction pathway, S28

Uyemoto, J. K., S66

Uzunovic, A., S9, S26, S79

Vaillancourt, L., 1125, S13

Vakalounakis, D. J., 161

Valerianella locusta, root and stem rot, aerial transmission by shore flies, 476

Valkonen, J. P. T., 462

Valverde, R. A., S47, S72, S73

van Berkum, P., S99

van Bruggen, A. H. C., S86

Vance, P., S107

Vandemark, G. J., S80

van de Mortel, M., S80

van den Bosch, F., 495

Vander Kooi, K., S50

van der Merwe, P. J. A., S55

van der Vlugt, R. A. A., 148

van der Werf, W., 789, 868, 1104

van der Zwet, T., S102

VanEtten, H. D., S32

Vann, S. R., S96

van Zyl, L. M., S80

Vargas, J. M., Jr., S61

Vavrina, C. S., S41

Vazquez, A., S60

Vazquez, M. R., S9

Veilleux, L. M., S80

Velaquis, L., S86

Velasquez, L., S80

Venette, J. R., S107

Venturia inaequalis

-on apple: infection time, cultivar effect, S20; prediction using sampling technique, S47

- ascospores, concentration and lesion relation, S13

-fungicide resistant strains, molecular basis, S70

—on Malus spp., phylogeny and rDNA analysis, 100 
-melanin pigment, characterization, S23

-population genetics, microsatellite markers, 748

Vereijken, P. F. G., 141

Vernon, P. R., S17

Verticillium dahliae

-on crucifers, isolate comparison, S7

-on eggplant: nitrogen effect, S26; poultry compost amended soil, S99

—host range specificity, 1218

-microorganisms antagonistic to, melanolytic activity, S72

-pathogens on nonhosts, S7

-in potato: populations in Ontario, S54; soil moisture and host resistance, 782

—on tomato, tolerance, S74

-vegetative compatibility groups, in Solanaceae, S78

Vesonder, R. F., S80

Vetten, H. J., 148

Vicedo, B., 286

Vicia faba, chocolate spot, screening technique, S55

Vidaver, A. K., S39

Vigna unguiculata, cucumber mosaic virus, virulence and amino acid change, 1186

Viji, G., S78, S80

Vincelli, P., S66

Viquez, O. M., S61

Viroid, detection, RT-PCR-probe capture hybridization, S71

Viruses

- begomoviruses, phylogenetically informative sequences, core coat protein sequence, S91

-luteovirus, on forage legumes, characterization, 374

- potyviruses, host range and coat protein, amino terminus role, $\mathrm{S} 79$

-RNA, dsRNA templates, cDNA cloning, S89

- tospoviruses, phylogeny, S6

Vivar, H., S15

Voegtlin, D. J., S34

Voelsing, K. J., S44

Voland, R. P., 1127

Völksch, B., 360

Vollmer, S. S., S60

von Amsberg, H., S81

Vorsa, N., S83

Vujanovic, V., S81

Wajahatullah, M. K., S81

Wakeman, R. J., S9

Walcott, R. R., S81, S96

Walk, T. E., S96

Walker, N. R., 613

Walker, S. G., S81

Walker, S. L., S81

Walkinshaw, C. H., S82, S96

Wall, G. C., S82

Walls, F. R., S98

Walsh, J. A., S67

Wang, B., S82

Wang, G. Y., S82

Wang, H., S82

Wang, J.(Calif.), 1022

Wang. J. (Ky.), S58

Wang, J.-F. (Taiwan), 320

Wang, K., S82

Wang, Q., S87

Wang, R. Y., 564

Wang, S., S82

Wang, T.-B., S4

Wang, X. (Kans.), S106

Wang, X. (Mich.), S83

Wang, X. (N.C.), S82

Wang, X. B. (Canada), S83

Wang, Y. (S.C.), S38

Wang, Y. L. (China), S86

Wangai, A. W., S83

Warokka, J. S., S37

Wasilwa, L. A., S83
Watermelon, gummy stem blight, fungicides, S95

Watkins, J. E., S69

Watrud, L. S., 782

Watts, J., S63

Wayadande, A. C., 1144

Wearing, L. P., S83

Webb, C. R., 30

Webb, D. R., 894

Webb, S. E., S62, S83

Weber, E. L., S47, S102

Webster, R. K., 176

Wedge, D. E., S94, S96

Weeden, N. F., S54

Wegulo, S. N., S56, S83

Weiland, J. J., 176

Weingart, H., 360

Weinzier, R. A., S34

Weisz, J. B., S66

Weisz, R., 1112

Welham, S. J., S24

Weller, D. M., 470, S22, S35, S63

Weller, J., 884

Wellman-Desbiens, É., S84

Welsh onion yellow stripe virus, on onion, strain of shallot yellow stripe virus, 148

Werner, N., S52, S103

Westphal, A., S84

Weststeijn, E. A., 156

Whalen, J., S101

Wheat

- bacterial leaf streak, severity and phyllosphere relation, 131

—disease management, new system, S46

- diseases of, Pseudomonas fluorescens, transformation of genes, S35

-durum, Fusarium head blight, chromosome substitution, S74

—dwarf bunt, resistance source, S28

- eyespot pathogens, detection methods, S5

— fungicides for, seeds and leaves, S10

-Fusarium head blight: deoxynivalenol, weather data predictions, S69; fungicide timing, S30; previous crop and tillage effects, S21; resistance in successive cycles, S32; spray nozzles and fungicides for control, S106

-Fusarium spp., nivalenol and deoxynivalenol production, S55

- head blight, modelling of disease foci, 74

- leaf spot complex, in Canada, 840

- leaf wetness, disease management, 668

— pathogen dispersal, aerial, combine harvest, S105

- powdery mildew, race-specific resistance, residual effect, 533

- Pseudomonas fluorescens in rhizosphere, population density and diacetylphloroglucinol, 470

- root rot, conservation tillage effect in Mexico, S52

- scab: Fusarium head blight resistance, molecular markers, 343; resistance screening, S81

- seed treatments and foliar fungicides, Maryland, S100

- stem rust: nonsuppression of resistance, gene Lr34, 518; resistance gene Sr26, tagging, S89

- stripe rust: planting density and genotype mixture, analysis, S26; two resistance genes, S56

-take-all: management in Arkansas, S53; microbial buffer in management, S21; seed treatment, fungicide efficacy, model, 954

- tan spot: characterization, review, 444; genetic analysis of toxin insensitivity, 293

- tan spot and Stagonospora blotch, infection period model, S20

Wheat streak mosaic virus

-eriophyid mite transmission, transcripts, 1182

-tolerance and resistance, $\mathrm{S} 61$

White, D. G., S52

White, F. F., S67, S84

White, J. F., Jr., S77

Wicklow, D. T., S36

Widmer, T. L., S1, S84
Widstrom, N. W., S31

Wieberg, A., S107

Wiersma, H. I., S84

Wijbrandi, J., 156

Wilcox, W. F., S6, S23, S84, S85

Williams, A. J., S84

Williamson, S. M., S3, S85

Williamson, V. M., 68

Williams-Woodward, J., S49

Willis, D. K., S34, S85

Willits, D. A., 212

Willment, J. A., 695

Wills, N., S84

Wilson, J. P., 450, S85, S96

Wilson, L. L., 555

Wilson, M. (Ala.) S11

Wilson, M. (Colo.), S89

Wilson, W. J., S63, S85

Winberg, R. M., S60

Windels, C. E., S8, S104

Wingfield, B. D., S73, S75

Wingfield, M. J., S2, S9, S73, S75, S80

Wintermantel, W. M., S85

Wisler, G. C., S57, S85

Wit, R., 1131

Wolf, T. M., S42

Woloshuk, C. P., 908, S25, S72

Wolyn, D., S33

Wong, F. P., S85

Wong, S.-M., 522, S38

Woods, D. L., S40

Workneh, F., 204, 844, S85

Wraith, S. J., S107

Wright, N. S., S29, S99

Wu, B. (Pa.), S80

Wu, B. M. (Calif.), S86

Wu, L., 653

Wu, W., S80

Wuest, P. J., S3, S12, S98

Wurms, K., 728, S51

Wyatt, J. E., S93

Wyatt, S. D., S44, S91

Wydra, K., 591

Wyss, G. S., S86

Xanthomonas spp.

- $X$. axonopodis, chromosomal gene transfer, conjugation, in pepper and tomato, 1044

-X. campestris: on anthurium, biocontrol, 366; on anthurium, temperature effect, 1007; on Araliaceae, strain heterogeneity, 646; on bell pepper, near-isogenic lines, major resistance genes, 1066; on carrot, copper sensitivity, S59; on cassava, semiselective medium for isolation, 591; on crucifers, pheromone and pig gene cluster, S61; on crucifers, suppression by cauliflower seed bacteria, S60; on English walnut, genetics, S46; leaf colonization, 353; on lettuce, transplant production, S84; pathovar differentiation, PCR, S76; pathovars, discrete, S39; on pepper, resistance and copper application, disease detection, S100; on pepper, resistance and PCR analysis, S57; on tomato and pepper, gene expression and colonization, S89; on tomato and pepper, multiphasic analysis in Caribbean and Central America, 328; on tomato and pepper, species differentiation, 16S-23S spacer and groEL genes, S48

$-X$. oryzae: on rice, avirulence genes, $\mathrm{S} 4$; on rice, genotypic and pathotypic diversity, 687; on rice, insertion elements, S67; on rice, phospholipase D distribution, S106; on rice, primary disease gradients, 64; on rice, strain distribution in Korea, 928; virulence and avirulence genes, gene-for-gene manner, S84

$-X$. translucens, on wheat, phyllosphere population, 131

Xia, J. Q., S7, S86

Xia, X., 660 
Xiao, C. L., S45, S86

Xie, W., S1

Xu, H., S86

$\mathrm{Xu}, \mathrm{R} ., \mathrm{S} 86$

$\mathrm{Xu}, \mathrm{T}$., $\mathrm{S} 86$

Xu, X. L., S87

Xylella fastidiosa

-on oleander: leaf scorch caused by, 53; symptoms, cover photo, January

-on orange: strains in Brazil, S62; transgenic resistance, $\mathrm{S} 33$

—rDNA sequences, S15

Yamasaki, S. H., 74

Yamauchi, N., S87

Yan, Y., S87

Yan, Z., S65, S87

Yang, B., S84

Yang, C. H. (Calif.), S87

Yang, C.-H. (China), 673

Yang, D. Q., S26

Yang, X. B., 204, 811, 844, S68, S85, S87, S105, S107

Yang, Y., S45, S62, S82, S87

Yao, M. K., S87
Yarden, O., 631

Yates, I. E., S88

Yeh, H.-H., S67

Yelle, S., S87

Yildiz, Z., S20

Ying, Z., S19

Yoder, K. S., S88

Yoshida, T., S34

Yoshikawa, N., 136

Young, C. A., S58

Young, D. H., S85, S88

Young, J. C., 1028

Yourman, L. F., S88

Ypema, H. L., S16, S28, S93

Yu, X., S88

Yuen, G. Y., 817, S105, S106, S108

Yuen, J. M. F., S56

Yun, C. H., S67

Zadoks, J. C., 495

Zala, M., S88

Zambino, P. J., S89

Zeller, K. A., S23

Zenbayashi, K., S3

Zeyen, R., S80, S89
Zhan, J., 639

Zhang, A. W., 796

Zhang, J. (S.D.), S89

Zhang, J. X. (Okla.), S89

Zhang, R., S46

Zhang, S., S65, S67, S89

Zhang, Y. (Fla.), S89

Zhang, Y.-P. (Calif.), S66, S89

Zhang, Z., 817, S108

Zhao, G., S34

Zhao, Y., S12

Zheng, J., S12

Zhong, B., S76

Zhou, S., S90

Zhou, X. G., S90, S97

Zhu, B., S90

Zhu, L., S58

Zhu, W., S84

Ziegenhorn, S. L., S2

Zijlstra, C., 380

Zitter, T., S10

Zriba, N., S90

Zucchini lethal chlorosis virus, new in Brazil, 823

Zucchini yellow mosaic virus, replicase, host protein, $\mathrm{S} 83$ 